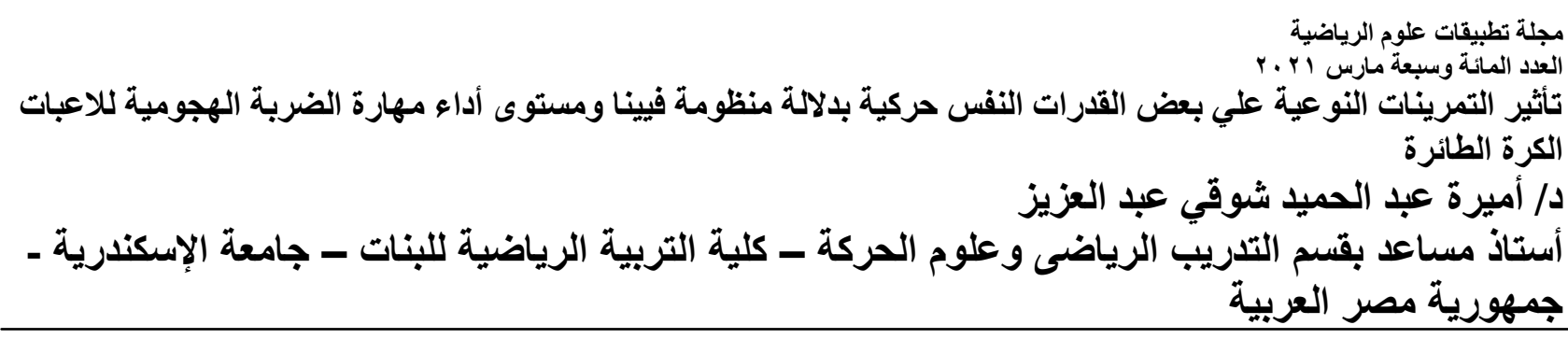

المقدمة ومشكلة البحث :

تتميز لعبة الكرة الطائرة بتنوع مهارتها الحركية الأساسية والتي تعتبر أحد الجوانب الهامة التي يينى على أساسها الجو انب الخططية للعبة ،

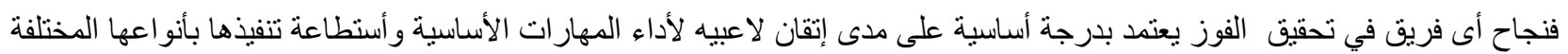

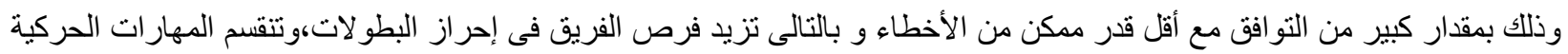

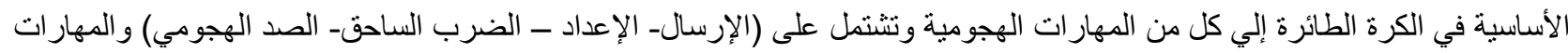

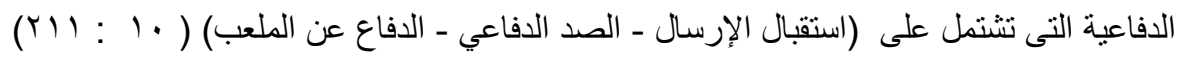

وتختلف المهارات الأساسية الهجومية في مدى أهميتها وترتيبها من حيث الحصول على نقاط المبار أ ألا أنها تتساوى جميعها فى ضرورة

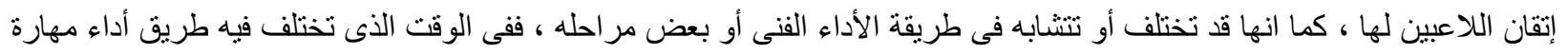

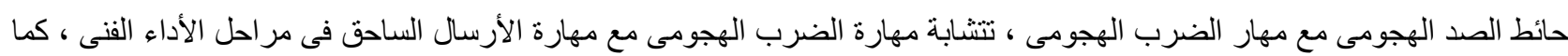

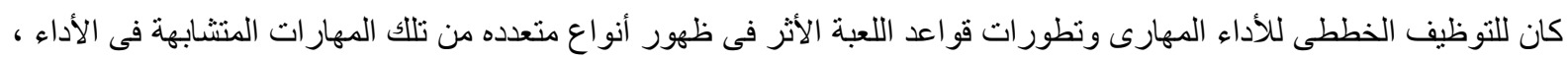

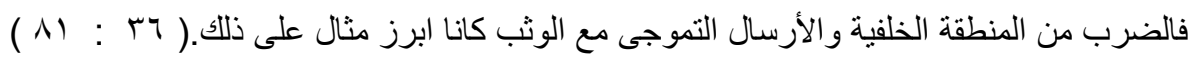

ويتوقف مستوى الأداء الحركى و المهارى للاعب الكرة الطائرة على إمكانية استغلال اللاعب لقدر اته البذنية لتحقيق أهداف المهارة وفقا

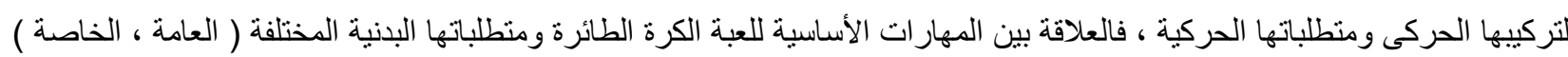

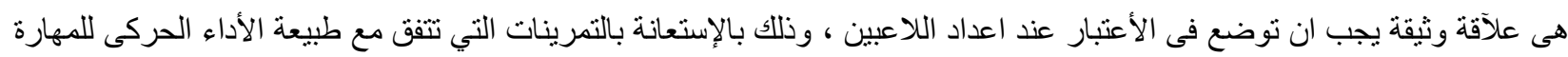

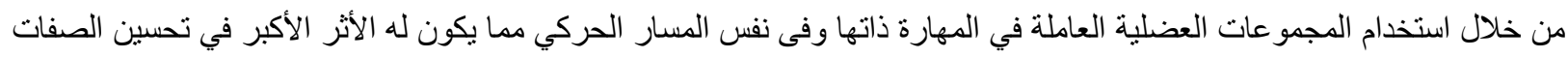

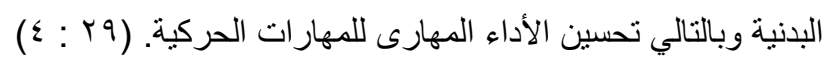

و تعد عملية الاعداد النفسي في المجال الرياضي اقتصاديا في الوقت و الجهد لتحقيق أفضل النتائج وذلك من خلال كونه برتبط بمجمل المكونات الجسمية والبدنية والنفسية وهناك عدة أساليب للتندريب والإعداد النفسي اذ يختلف كل اسلوب عن الاخر في كيفية تطبيقه ولكنها

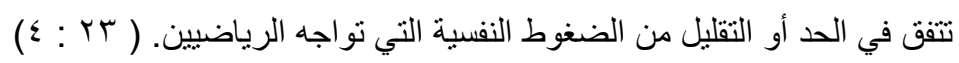
وتعرف القدر ات النفس حركية بأنها " إمكانيات الفرد البدنية والمهارية والحركية والإدر اكية الأصلية التي بمتلكها بصورة أولية والتي تحدد

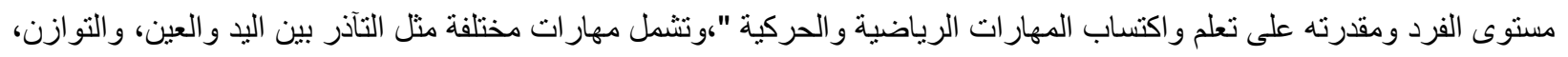
): 35 ) (اب 37 : 58(.وزمن رد الفعل التي تنشأ عن وحدة من الوظائف المعرفية والبدنية

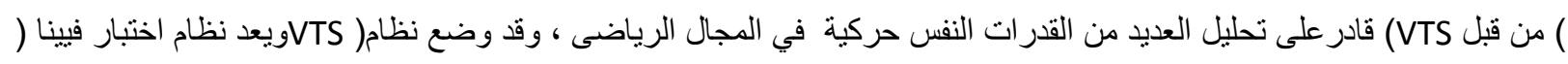

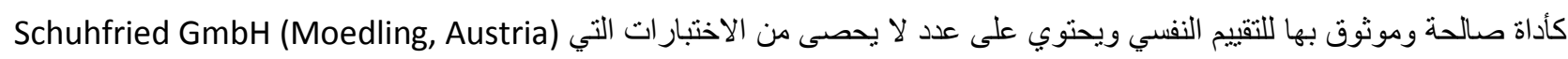

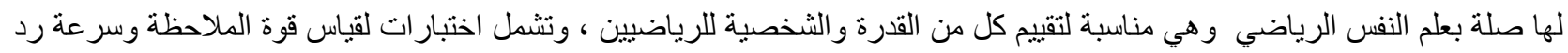

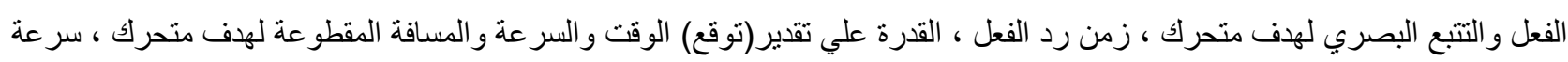

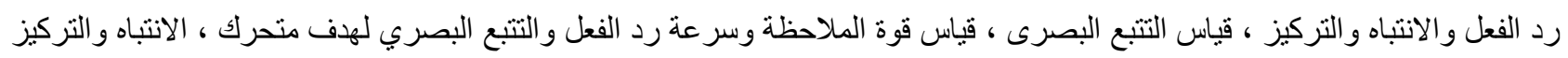

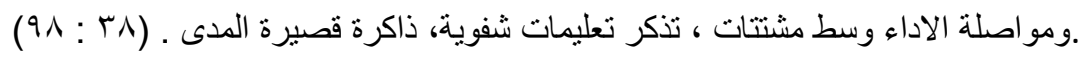




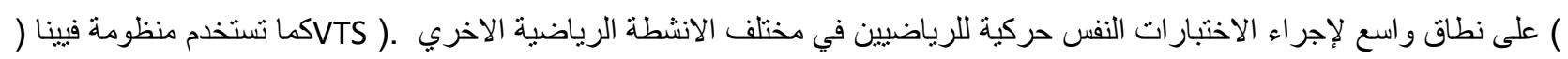
(ro: : .

، حيث و أصبح الهذف للوصول الي المستويات العليا هو إيجاد طرق لتشخيص قدرات اللاعبين بشكل موضوعي ورصد مستوى التقام لديهم تتطلب رياضات المستوى العالى وسائل التدريب الجديدة التي تمكن التقدم المستمر في قدر ات البدنية والنفسية للاعبات وذللك من خلال تطبيق

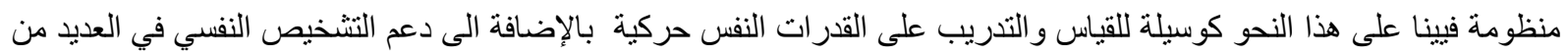
).

وتلعب التمرينات النوعية دورا هامة فى الارتقاء بمستوى الأداء المهارى و الوصول للمستويات العالية وذللك بما توفره من فرصة جيدة للارتقاء بمستوى الأداء ، فهى عبارة عن مجموعة من التمرينات و التدريبات التى نتشابه فى نكوينها الحركى و التركيب الديناميكي مع الأداء

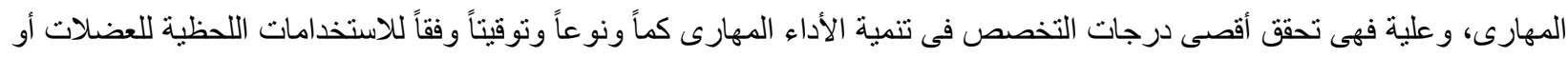

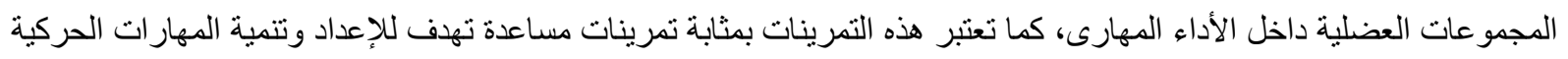

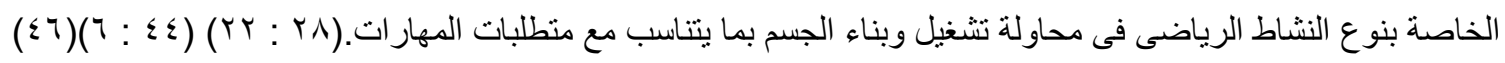
كما تساهم التمرينات النو عية فى العمل على تصحيح الأوضاع التى يتذذها الجسم اثناء الأداء المهارى الأمر الذى ينعكس فى المقام الأول تكنيك الأداء للمهار ات الحركية ، وتستخدم ايضا بغرض الإعداد و التمهيد لتعلم الحركات و المهار ات الخاصة بالانشطة الرياضية المختلفة. $(19: r \cdot)\left(1 \mu \Lambda: r^{\prime}\right)$

ونظر الأهمية الضربة الساحقة و الضربة الخلفية ومدى تأثير هم على نتائج المباريات ومن خلال عمل الباحثة فى الحقل التدريبى كمدربه

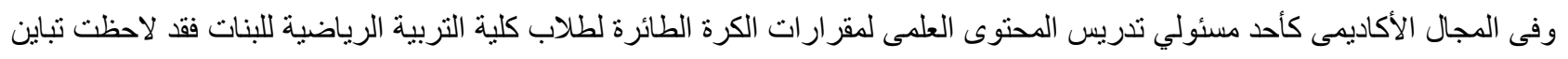

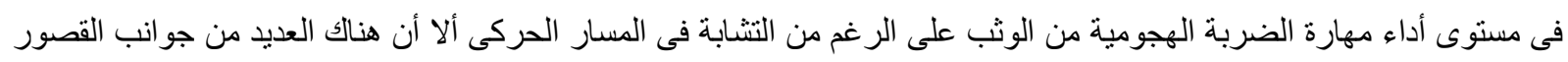

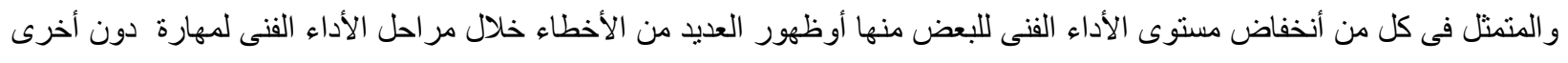

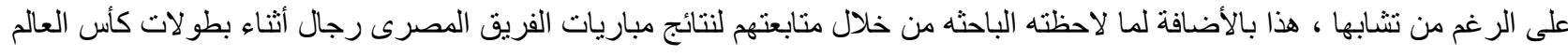

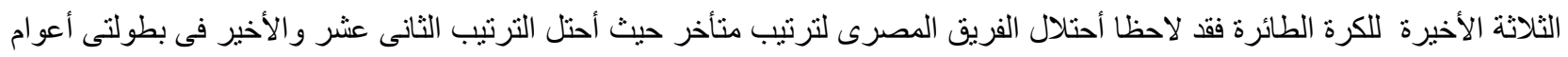

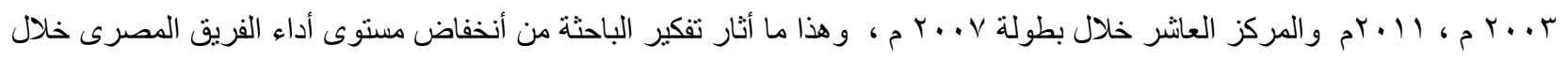

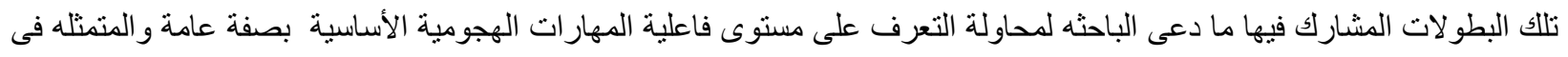

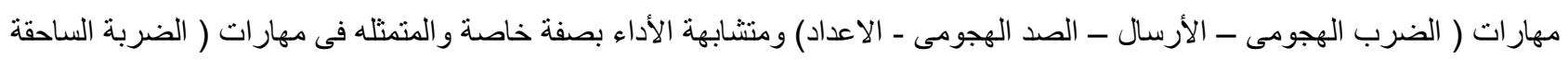

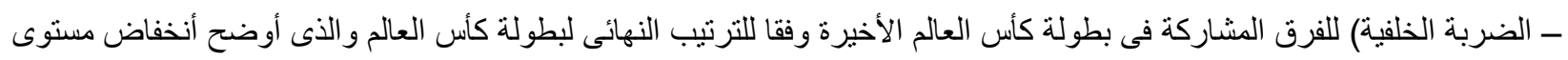

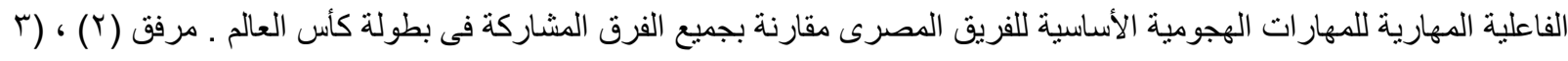
$(\varepsilon 0) \cdot($

هذا بالإضافة إلى أنه و بالر غم من تناول العديد من الدراسات و الأبحاث العلمية لمهارات الكرة الطائرة الهجومية من العديد من الأتجاهات

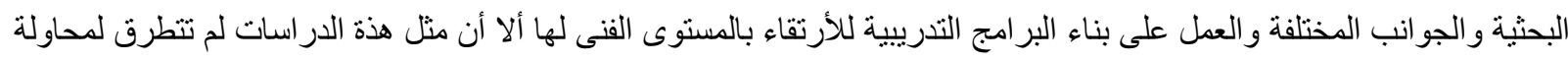

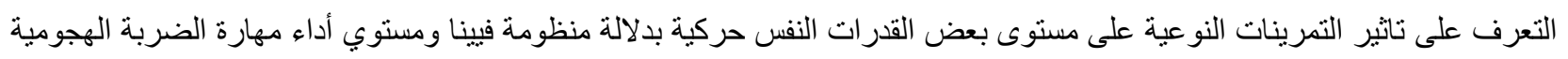
للاعبات الكرة الطائرة.

الأمر الذي دفع الباحثة للقيام بالمسح المرجعى للتعرف على الدراسات والأبحاث العلمية التى تناولت بناء البرامج التنريبية للأرتقاء

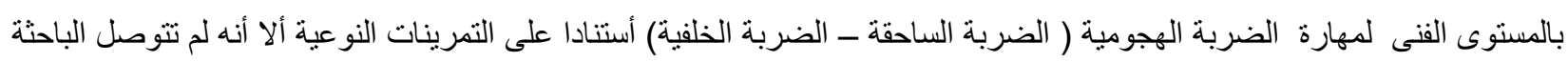

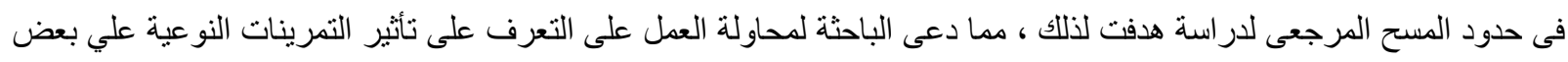

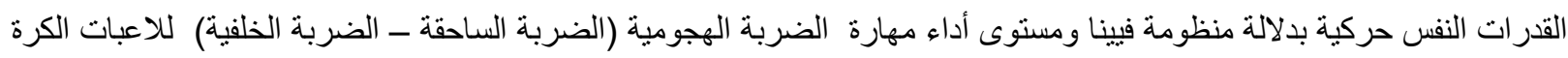

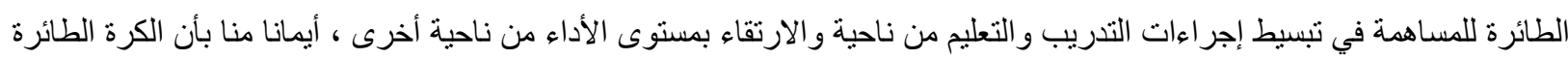

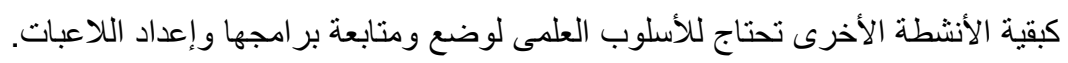




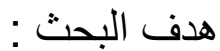

حددت الباحثة الهفف العام من البحث فى محاولة التعرف على" تأثير التمرينات النوعية علي بعض القدرات النفس حركية بلالة منظومة فيينا ومستوى أداء مهارة الضربة الهجومية للاعبات الكرة الطائرة " و الذى يمكن تحقيقه من خلال :

ا. ـ التعرف على دلالة الفروق بين القياس القبلى و البعدى للمجموعة البحث علي بعض القدرات النفس حركية بدلالة منظومة فيينا

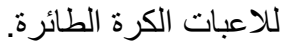

r. التعرف على دلالة الفروق بين القياس القبلى والبعدى للجموعة التجريبية علي مستوى أداء مهارة الضربة الهجومية (الضربة

$$
\text { الساحقة - الضربة الخلفية) للاعبات الكرة الطائرة. }
$$

\section{فرضا البحث:}

1. توجد فروق دالة إحصائياً بين القياسين القبلى و البعدى لمجموعة البحث لصالح القياس البعدى فى بعض القدرات النفس حركية بدلالة منظومة فيينا للاعبات الكرة الطائرة.

r. . توجد فروق دالة إحصائياً بين القياسين القبلى و البعدى لمجمو عة البحث لصالح القباس البعدى فى مستوى أداء مهارة الضربة الهجومية (الضربة الساحقة - الضربة الخلفية) للاعبات الكرة الطائرة.

إجراءات البحث:

أولاً : منهج البحث:

استخدمت الباحثة المنهج التجريبى ذو التصميم التجريبى للمجموعة الواحدة بالقياسات القبليه البعدية وذلك لملائمته لطبيعة

ثانياً:مجالات البحث:

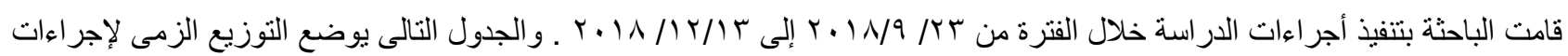
البحث :-

\section{جدول (1)}

\section{التوزيع الزمنى لإجراءات البحث}

\begin{tabular}{|c|c|}
\hline الفترة الزمنية & الإجر اءات \\
\hline 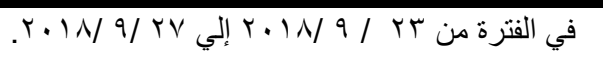 & تم إجر اء القياسات القبلية \\
\hline 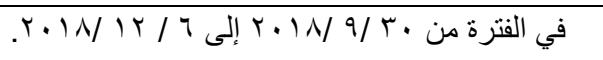 & تم إجر اء التجربة الأساسية \\
\hline 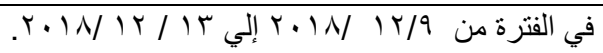 & تم إجر اء القياسات البعدية \\
\hline
\end{tabular}

قامت الباحثة بتنفيذ البرنامج التدريبي في ملاعب الكرة الطائرة بكلية التربية الرياضية للبنات جامعه الأسكندرية.

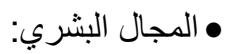

فريق الكرة الطائرة بكلية التربية الرياضية للبنات جامعه الأسكندرية. 
ثالثا: عينة البحث:

تم اختبار عينة البحث بالطريقة العددية لفريق كلية التربية الرياضية للبنات للكرة الطائرة والمشارك في بطولتي الكليات المتخصصة

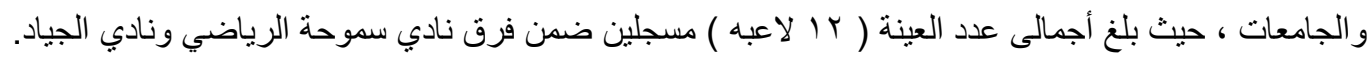

رابعا : أدو ات البحث:

من خلال الأطلاع على المر اجع العلمية والأبحاث العلمية المتخصصة وشبكة المعلومات المتاحة للباحثة فى مجال تدريب الكرة الطائرة

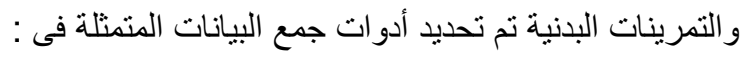

ا - تم تحديد اختبار ات منظومة فيينا (Vienna test System) لقياس القدرات النفس حركية قام بترجمته ووضعه في صورته

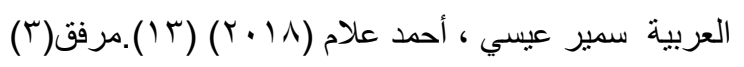

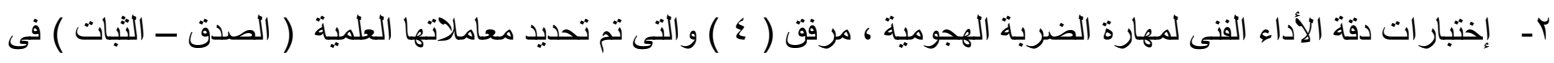

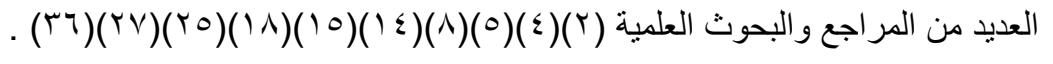

\section{الأجهزة و الوسائل المستخدمة في البحث:}

استعانت الباحثه عند تطبيقها للبرنامج التدريبى المقترح مجمو عة من الوسائل الادوات المساعدة والمتمثلة فيما يلى :
* كرات طبية مختلفة الأوزان.

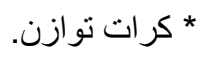
* ساعة إيقاف. * ميزان طبي.

* شر ائط وحبال مطاطة

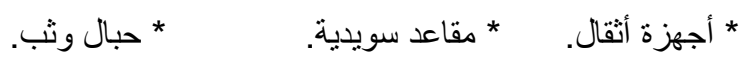

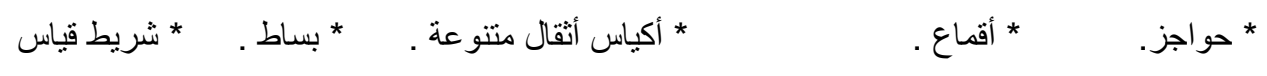

* ملعب الكرة الطائرة مغلق كامل التجهيز (الثبكة- القو ائم- الثرئط- r عصا هو ائية) . * صناديق مختلفة الإرتفاعات.

خامساً: تجانس العينة:

تم إجر اء التجانس لعينة البحث في المتغيرات الأساسية والقدرات النفس حركية و مهارة الضربة الهجومية بالإضافة لمستوى الأداء الفنى لهذة

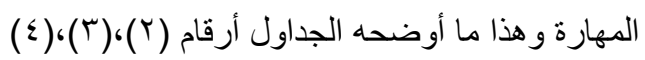

\begin{tabular}{|c|c|c|c|c|c|c|c|}
\hline $\begin{array}{l}\text { الاختلافـ\% معامل } \\
\text { مل }\end{array}$ & التفلطح معامل & الألتواء معامل & الانحراف & الحستوسط & القياس & الالالات الإحصائية & \\
\hline $17.77 \%$ & 1.78 & -2.14 & 3.65 & 20.54 & (سنة) & 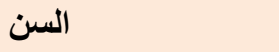 & \multirow{4}{*}{ الأستغيرة } \\
\hline $16.38 \%$ & 2.67 & 0.45 & 28.18 & 172.00 & (سم) & الطول & \\
\hline $12.61 \%$ & -1.45 & -0.89 & 8.67 & 68.75 & (كجم) & الوزن & \\
\hline $16.19 \%$ & 0.43 & 1.36 & 1.24 & 7.66 & (سنة) & عدد سنوات الممارسة & \\
\hline
\end{tabular}

جدول رقم (r)

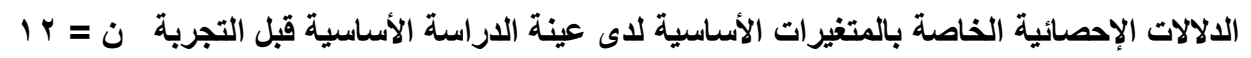




\section{أميرة عبد الحميد شوقى عبد العزيز}

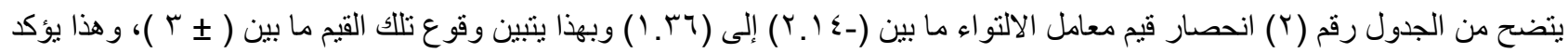

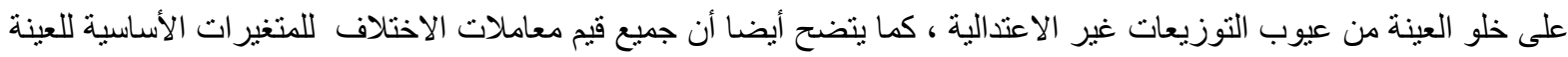

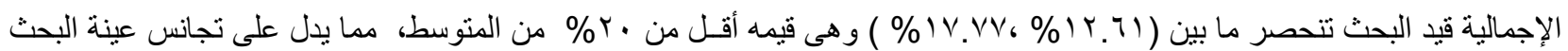
فى جميع المتغير ات قيد البحث.

جدول (r) (2) (2)

(الدلات الإحصائية الخاصة القدرات النفس حركية بدلالة اختبارات منظومة فيينا Vienna test System ( لع العينة الإجمالية قيد البحث

\begin{tabular}{|c|c|c|c|c|c|c|c|}
\hline $\begin{array}{l}\text { الاختلاف معامل \% } \\
\text { \% }\end{array}$ & التفطح & الالتواء معامل & المعياري & الحسابي & القياس & الالالات الإحصائية & \\
\hline$\% 10.57$ & 1.25 & -1.55 & 8.56 & 81.00 & (ثانية) & رد الفعل زمن & \multirow{4}{*}{ إختبارزمن رد الفعل } \\
\hline$\% 11.90$ & 0.54 & 0.11 & 6.32 & 53.08 & (ثانية) & زمن الاستجابة الحركى & \\
\hline$\% 6.83$ & -1.51 & 0.34 & 5.11 & 74.83 & (ثانية) & رد الفعل قياس التثتت اثثاء زمن & \\
\hline$\% 13.91$ & 1.04 & 1.15 & 6.85 & 49.25 & (ثانية) & الاستجابة الحركى قياس التثُتت اثثاء زمن & \\
\hline$\% 7.01$ & -0.64 & -1.05 & 6.32 & 90.08 & (ثانية) & المستغرق الزمن & \multirow{2}{*}{ 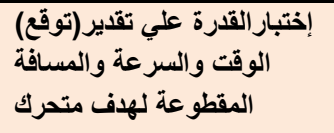 } \\
\hline$\% 17.94$ & -0.99 & -0.52 & 7.10 & 39.58 & (ثاثية) & الحركة المكانية المترقبة & \\
\hline$\% 19.69$ & -1.20 & -0.24 & 5.18 & 26.33 & (عدد) & الصحيحة الاستجابات عدد & \multirow{3}{*}{ ) إ مواصلة العمل وسط مشتتات الانتباه - التركيز } \\
\hline$\% 3.59$ & -1.10 & 0.53 & 3.02 & 84.00 & (ثانية) & وقت الاستجابات الصحيحة & \\
\hline$\% 11.30$ & -1.83 & 0.11 & 0.87 & 7.67 & (عدد) & عدد الاستجابات الخاطئة & \\
\hline$\% 19.33$ & 0.56 & 0.35 & 6.02 & 31.17 & (عدد) & الاستجابات الصحيحة & إختبار تذكر تعليمات شفوية، \\
\hline$\% 5.96$ & -0.29 & -0.05 & 4.24 & 71.17 & (ثانية) & متوسط معدل السرعة اثثاء اداء الاختبار & \multirow{3}{*}{$\begin{array}{l}\text { اختبار توافق الذراعين مع العين (اليدين معا) }\end{array}$} \\
\hline$\% 4.58$ & -1.15 & 0.47 & 3.87 & 84.58 & (ثانية) & معدل الدقة اثثاء اداء الاختبار متوسط & \\
\hline$\% 17.39$ & 0.22 & -0.43 & 6.26 & 36.00 & (ثانية) & اللاقة أثناء أداء اجمالى نسبة الخطاً & \\
\hline$\% 6.98$ & -1.53 & -0.40 & 3.55 & 50.92 & (عدد) & اجمالى معدل الخطاً & \multirow{3}{*}{ إختبارتوافق الذراعين مع العين } \\
\hline$\% 7.30$ & -1.01 & -0.70 & 4.45 & 61.00 & (عدد) & معدل الخطأ لليا اليسرى & \\
\hline$\% 9.52$ & -0.77 & 0.20 & 5.77 & 60.67 & (عدد) & معدل الخطأ لليد اليمنى & \\
\hline
\end{tabular}


أميرة عبد الحميد شوقى عبد العزيز

\begin{tabular}{|c|c|c|c|c|c|c|c|}
\hline $\begin{array}{l}\text { الاختلاف معامل } \\
\text { \% معل }\end{array}$ & التقلطح معامل & الالتواء معامل & الاتحراف المعياري & الحسابي & القياس & الالالات الإحصائية & \\
\hline$\% 10.56$ & -1.85 & 0.22 & 6.51 & 61.67 & (عدد) & عدد الاخطاء & \\
\hline$\% 10.34$ & 1.51 & 1.15 & 5.82 & 56.25 & (عدد) & عدد الاخطاء اليد اليسري & \\
\hline$\% 19.24$ & -0.93 & -0.56 & 8.82 & 45.83 & (عدد) & عدد الاخطاء اليد اليمني & \\
\hline$\% 18.04$ & -0.57 & -0.32 & 8.36 & 46.33 & (عدد) & استجابات صحيحة & إختبارقوة الملاحظة - سرعة رد الفعل - تتبع بصرى \\
\hline$\% 19.47$ & -1.64 & -0.03 & 8.29 & 42.58 & (ثانية) & متوسط الانحراف للزاوية & \multirow{7}{*}{ إختبار التوافق الحس حركي } \\
\hline$\% 15.42$ & 1.29 & -0.81 & 6.39 & 41.42 & (ثانية) & متوسط الانحراف الافقى & \\
\hline$\% 11.28$ & -1.67 & -0.34 & 2.02 & 17.92 & (ثانية) & متوسط الانحراف الرأسى & \\
\hline$\% 6.08$ & -0.65 & -0.44 & 4.52 & 74.33 & (ثانية) & مدى التثتت فى انحراف & \\
\hline$\% 7.59$ & 0.28 & -0.32 & 5.21 & 68.67 & (ثانية) & مدى التشتت فى الاتحراف الافقى & \\
\hline$\% 10.35$ & -1.44 & -0.22 & 1.98 & 19.08 & (ثانية) & مدى التثتت فى الانحراف الرأسى & \\
\hline$\% 6.90$ & -1.80 & 0.45 & 5.15 & 74.75 & (ثانية) & الوقت المستهلك فى نطات التصميم & \\
\hline
\end{tabular}

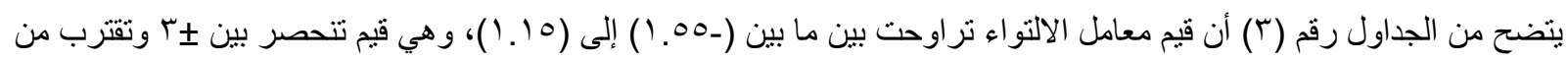

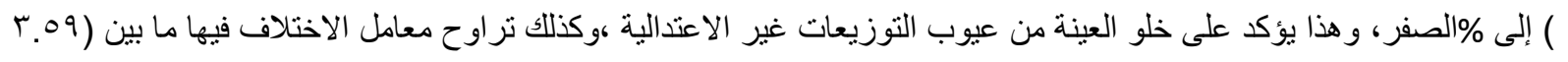

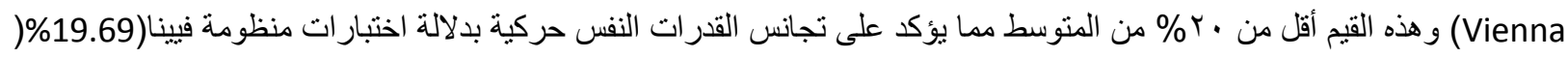
) الخاصة بالعينة قيد البحث قبل التجربة.

جدول رقم (؛)

الالالات الإحصائية الخاصة بمستوى أداء مهارة الضربة الهجومية لاى

عينة الاراسة الأساسية قبل التجربة

\begin{tabular}{|c|c|c|c|c|c|c|c|c|}
\hline $\begin{array}{l}\text { الاختلاف \%عامل \% } \\
\text { \% }\end{array}$ & التفططح & الألتواء & الالحراف & الحسابى & القياس & ات الإحصائية & & \\
\hline$\% 17.53$ & 0.53 & 1.23 & 0.63 & 3.60 & (درجة) & إلى مركز ( 1 ) & \multirow{2}{*}{ من مركز (؟) } & \multirow{2}{*}{ لضربة الساحقة } \\
\hline$\% 12.76$ & 1.08 & -0.47 & 0.83 & 6.48 & (درجة) & إلى مركز ( ) & & \\
\hline
\end{tabular}


أميرة عبد الحميد شوقى عبد العزيز

\begin{tabular}{|c|c|c|c|c|c|c|c|c|}
\hline$\% 18.32$ & 0.20 & 0.14 & 1.06 & 5.80 & (درجة) & إلى مركز ( " ) & & \\
\hline$\% 18.95$ & -1.05 & 0.51 & 0.81 & 4.26 & (درجة) & إلى مركز ( 1 ) & \multirow{3}{*}{ من مركز (؛) } & \\
\hline$\% 10.98$ & 2.13 & -0.30 & 0.72 & 6.57 & (درجة) & إلى مركز (• ) & & \\
\hline$\% 13.04$ & -0.12 & 0.92 & 0.74 & 5.66 & (درجة) & إلى مركز ( " ) & & \\
\hline$\% 13.48$ & 1.31 & -1.54 & 0.74 & 5.48 & (درجة) & إلى مركز ( 1 ) & \multirow{3}{*}{ من مركز (1) } & \multirow{6}{*}{ الضربة الخلفية } \\
\hline$\% 18.45$ & 0.46 & 0.18 & 0.85 & 4.59 & (درجة) & إلى مركز (• ) & & \\
\hline$\% 14.72$ & -1.81 & -0.31 & 0.90 & 6.12 & (درجة) & إلى مركز ( " ) & & \\
\hline$\% 17.15$ & 0.26 & 0.56 & 0.75 & 4.35 & (درجة) & إلى مركز ( 1 ) & \multirow{3}{*}{ من مركز (") } & \\
\hline$\% 19.60$ & -1.02 & 0.42 & 1.05 & 5.34 & (درجة) & إلى مركز (• ) & & \\
\hline$\% 8.24$ & 7.15 & -2.38 & 0.54 & 6.56 & (درجة) & إلى مركز ( " ) & & \\
\hline
\end{tabular}

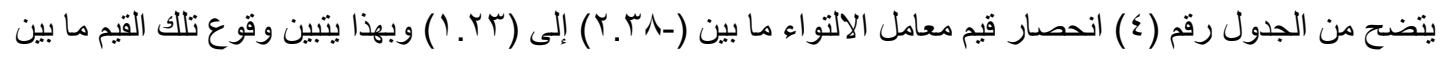

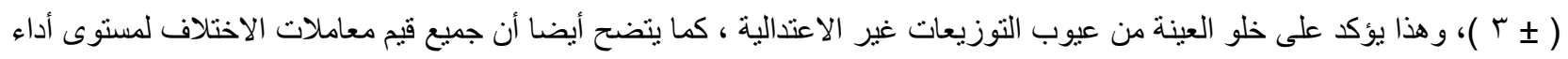

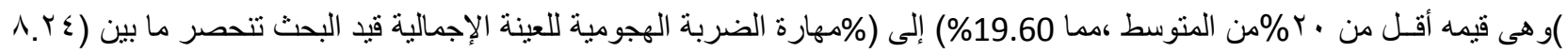
يدل على تجانس عينة البحث فى مهارة الضربة الهجومية قيد البحث.

سادساً : البرنامج التدريبى المقترح:-

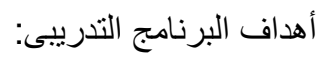

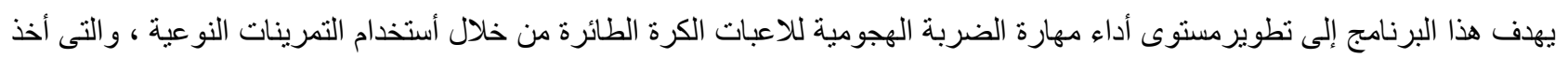

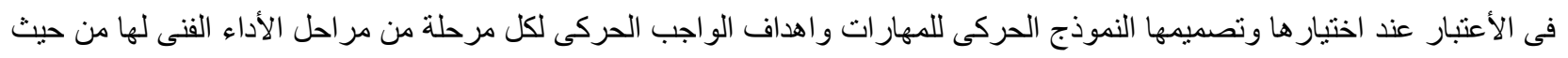

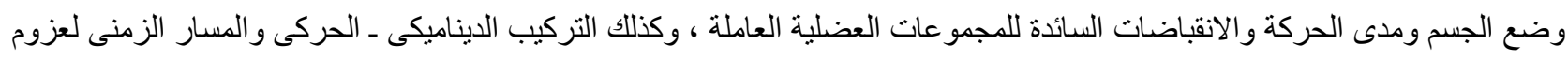

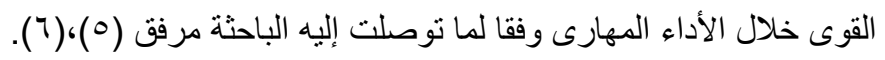

الأسس التى نم مر اعاتها أثناء وضع البرنامج المقترح:

حرصت الباحثه عند وضع برنامجها مر اعاة الأسس التالية:

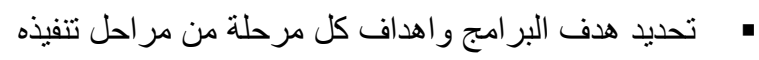

• تحديد اهم واجبات التنريب مع مر اعاة الترتيب و التدرج فى التمرينات النوعية

• مراعاة مبدأ الفروق الفردية بين أفراد العينة.

• ملائمة محتوى البرنامج لمستوى عينة البحث من حيث السن والنوع و المستوى

• مرونة البرنامج ومناسبته للتطبيق العملى.

• مر اعاة عو امل الأمن و السلامة.

• الاهتمام بقو اعد الإحماء و التهيئه. 


$$
\text { • تنظيم عملية التدريب وتنوع التدريبات المستخدمة }
$$

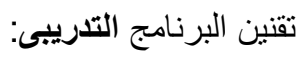

$$
\text { • الفترة التنريبية المناسبة لتطبيق البرنامج التنريبى : تم تحديد فترة تتفيذ البرنامج التدريبى خلال فترة الإعداد . }
$$

تم تحديد عدد الاسابيع المناسبة للبرنامج و البالغ عددها (r T) اسبوع حيث تم توزيعها على المر احل المختلفة للبرنامج المقترح

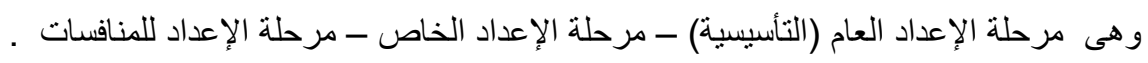

$$
\text { • عدد مرات التدريب أسبو عيا للبرنامج التدريبى :(ع) وحدات تدريبية. }
$$

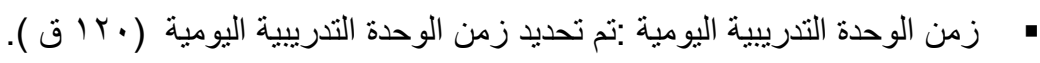
• مكونات الوحدة التدريبية اليومية : تم تحديد مكونات الوحدة التدريبية اليومية وتتقسم إلى :

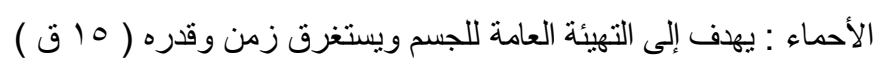

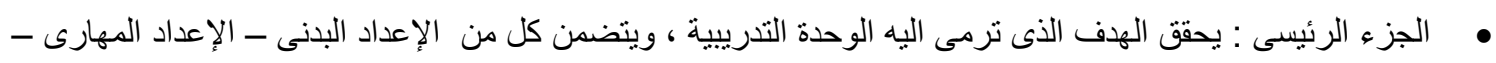

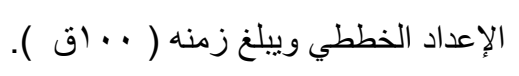

الختام ( التهيئة ) : يهدف إلى محاولة العودة الى الحاله الطبيعية وذلك من خلال تمرينات الاسترخاء ويستغرق زمن

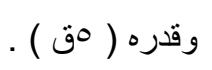

\begin{tabular}{|c|c|c|c|c|}
\hline \multicolumn{2}{|c|}{ عدد مرات التكرار } & \multicolumn{2}{|c|}{ النسبة المئوية } & درجة الحمل \\
\hline مرة واحدة & \multirow{3}{*}{ من 1 _- مرات } & $\% 1 \cdots-91$ & \multirow{3}{*}{$\% 1 \cdots-9}$. & \multirow{3}{*}{ الأقصى } \\
\hline مرتين & & $\% 9 \wedge-94$ & & \\
\hline (ץ' ) مرات & & \%94_-१ & & \\
\hline
\end{tabular}

• طريقة التدريب المستخدمة : تم تحديد طريقة التدريب الفترى مرتفع الثندة ومنخفض الثندة لمناسبة لطبيعة البحث وهدفة

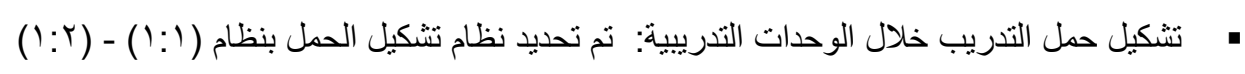
• الاحمال التدريبية : تم تحديد كل من الحمل

$$
\text { 4 }
$$

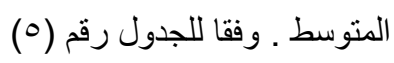

\section{جدول (0)}

درجات حمل التدريب المستخدمة فى البرنامج والنسب المئوية وعدد مرات تكرار التمرين 
أميرة عبد الحميد شوقى عبد العزيز

\begin{tabular}{|c|c|c|c|c|}
\hline ( ) مرات & & $\% 9 \leq-94$ & & \\
\hline (0 ) مرات & & $\% 94-q$. & & \\
\hline ( ' ) مرات & \multirow{5}{*}{ من ' - · ا مرات } & $\% q \cdot-\Lambda v$ & \multirow{5}{*}{$\% q \cdot-v_{0}$} & \multirow{5}{*}{ الأقل من الأقصى } \\
\hline ( ) مرات & & $\% \wedge \vee-\wedge \varepsilon$ & & \\
\hline ( ) مرات & & $\% \wedge \leq-\wedge 1$ & & \\
\hline (9 (9) مرات & & $\% \wedge 1-\vee \wedge$ & & \\
\hline (1 (1) مرات & & $\% \vee \wedge-\vee \diamond$ & & \\
\hline (11) مرة & \multirow{10}{*}{ من 11 - •r مرة } & $\% V_{0}-V Y .0$ & \multirow{10}{*}{$\%$ vo _ 0.} & \multirow{10}{*}{ المتوسط } \\
\hline (Y (Y) مرة & & $\%$ VY.O-V. & & \\
\hline (r (1 ) مرة & & $\%$ \%・-TV.0 & & \\
\hline (1 (1) مرة & & $\% 7 V .0-10$ & & \\
\hline (10) مرة & & $\%$ \% & & \\
\hline (1 (1) مرة & & \% Tr.0-4. & & \\
\hline (IV) مرة (IV) & & $\%$ \% - - V.0 & & \\
\hline (1 (1) مرة & & $\% \Delta V .0,00$ & & \\
\hline (19) مرة & & $\% \Delta \theta_{0} \Delta Y_{\text {. }}$ & & \\
\hline ( · ) مرة & & $\%$ or.o_o. & & \\
\hline
\end{tabular}

تشكيل حمل التدريب فى البرنامج المقترح :-

* تتكيل شدة حمل التدريب وفقا لمر احل التدريب و الوحدات الأسبو عية للبرنامج التدريبيى المقترح

قامت الباحثه بتوزيع أحمال التدريب الخاص بالوحدات التنريبية الأسبو عية لفترة الإعداد العام والخاص و الإعداد للمنافسات وفقا لثدة الحمل فلثل و الذى يتضح فى الثكل النالى .

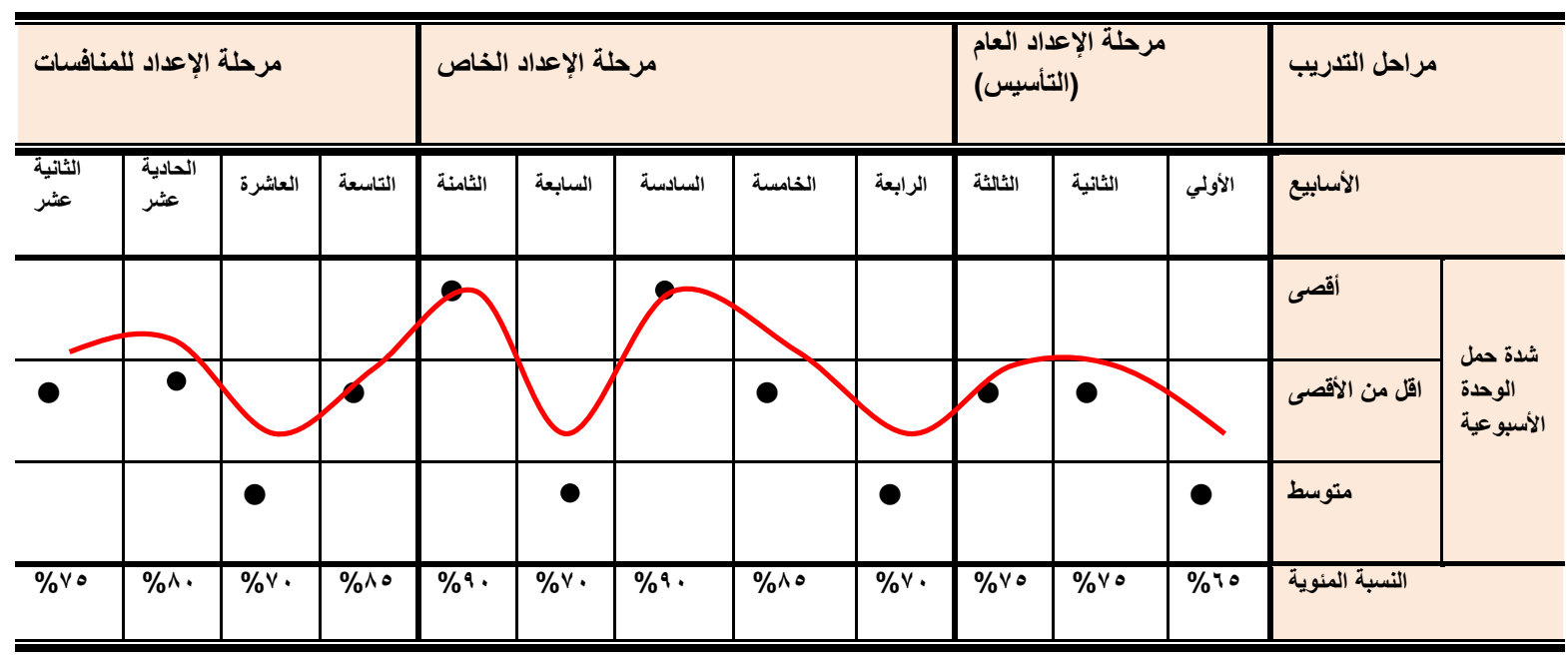

شكل (1) 
أميرة عبد الحميد شوقى عبد العزيز

تثكيل شدة حمل التدريب وفقا لمراحل التدريب والوحدات الأسبوعية للبرنامج التدريبيى المقترح 
أميرة عبد الحميا شوقى عبد العزيز

تثكيل شدة حمل التدريب وفقا لمر احل التنريب و الوحدات اليومية للبرنامج التدريبيى المقترح

قامت الباحثة بتوزيع أحمال التنريب الخاص بالوحدات التنريبية اليومية لفترة الإعداد العام والخاص و الإعداد للمنافسات وفقا للثكل التالى .

شكل ( r r ) دورة الحمل اليومية خلال أيام تنفيذ البرنامج التدريبي المقترح خلال مرحلة الإعداد العام (التأسيس)

\begin{tabular}{|c|c|c|c|c|c|c|c|c|c|c|c|c|c|}
\hline \multicolumn{4}{|l|}{ الثالث } & \multicolumn{4}{|l|}{ الثانى } & \multicolumn{4}{|l|}{ الأول } & \multicolumn{2}{|l|}{ الأسابيع } \\
\hline ir & 11 & 1. & 9 & $\wedge$ & $v$ & 1 & - & $\varepsilon$ & $r$ & r & 1 & وحدة اليومية & \\
\hline & & & & & & & & & & & & أقصى & \\
\hline & & & & & & & & & & & & اقل من الأقصى & سده حمل الومية \\
\hline - & & - & & - & & & - & & - & & - & متوسط & \\
\hline$\%$ \%० & $\%^{\wedge 0}$ & $\%$ \% & $\% \wedge$. & $\% \vee$. & $\% \wedge 0$ & $\%$ \%० & $\% \vee$. & $\% \vee 0$ & $\% 4$ & $\% \vee 0$ & $\% \circ$. & النسبة المئوية & \\
\hline
\end{tabular}

شكل ( r ) دورة الحمل اليومية خلال أيام تنفيذ البرنامج التدريبي المقترح خلال مرحلة الإعداد الخاص

\begin{tabular}{|c|c|c|c|c|c|c|c|c|c|c|c|c|c|c|c|c|c|c|c|c|c|}
\hline \multicolumn{4}{|l|}{ الثامن } & \multicolumn{4}{|l|}{ السابع } & \multicolumn{4}{|c|}{ السادس } & \multicolumn{4}{|c|}{ الخامس } & \multicolumn{4}{|l|}{ الرابع } & \multicolumn{2}{|l|}{ الأسابيع } \\
\hline rr & ri & r. & rq & r^ & rv & rq & ro & $r \varepsilon$ & $r \mu$ & rr & r) & r. & 19 & 11 & iv & 17 & 10 & $1 \leqslant$ & $1 \pi$ & الوحدة اليومية & \\
\hline & & & & & & & & & & & & & & & & & & & & أقصى & $1 ;$ \\
\hline & $\bullet$ & & - & & $\bullet$ & - & & • & & - & & - & - & & - & - & & $\bullet$ & $\searrow$ & اقل من الأقصى & الو الوحدة \\
\hline & & & & - & & & - & & & & & & & & & & - & & - & متوسط & \\
\hline$\% 90$ & $\% \wedge \wedge$ & $\% 90$ & $\%$ ^ब & $\% 40$ & $\%$ vo & $\%$ vo & $\%$ \%० & $\% \wedge$ ^० & $\% 90$ & $\%$ ^॰ & $\% 90$ & $\%^{\wedge}$ & $\%$ vo & $\% 90$ & $\% \wedge 0$ & $\%$ vo & $\% 10$ & $\% \wedge$. & $\%^{4}$ & النسبة المئوية & \\
\hline
\end{tabular}


أميرة عبد الحميد شوقى عبد العزيز

\begin{tabular}{|c|c|c|c|c|c|c|c|c|c|c|c|c|c|c|c|c|c|}
\hline \multicolumn{4}{|c|}{ الثانى عشر } & \multicolumn{4}{|c|}{ الحادى عشر } & \multicolumn{4}{|c|}{ العاشر } & \multicolumn{4}{|c|}{ التاسع } & \multicolumn{2}{|l|}{ الأسـابيع } \\
\hline ז & ro & $\leq 7$ & $\leq 0$ & $\varepsilon \varepsilon$ & $\varepsilon r$ & $\leqslant r$ & \&1 & $\varepsilon$. & rq & $r \Lambda$ & $r v$ & rq & ro & $r \varepsilon$ & rr & لوحدة اليومية & \\
\hline & & & & & & & & & & & & & & & & أقصى & شدة حمل \\
\hline & & & & & & & 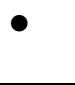 & & & & & & & $\bullet$ & - & اقل من الأقصى & الوالوحية \\
\hline$\bullet$ & & & $\bullet$ & & $\bullet$ & & & $\bullet$ & & - & - & & & & & متوسط & \\
\hline$\% 70$ & $\% \wedge$. & $\% \wedge \theta$ & $\% \vee$. & $\% \vee 0$ & $\% \vee$. & $\% \wedge \diamond$ & $\%{ }^{\wedge \Delta}$ & $\% \vee \cdot$ & $\% \vee 0$ & $\% \vee$. & $\% 70$ & $\% \wedge 0$ & $\% 9$. & $\% \wedge \Delta$ & $\% \wedge$. & النسبة المئوية & \\
\hline
\end{tabular}

التوزيع النسبي والزمنى لأجز اء الوحدة اليومية خلال مر احل البرنامج : البها

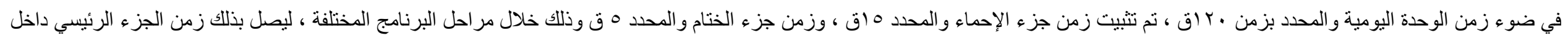

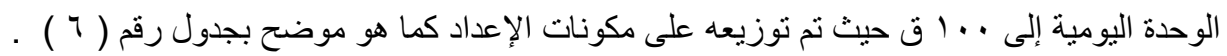

جدول (7)

التوزيع النسبي والزمني لأجزاء الوحدة اليومية خلال مراحل البرنامج

\begin{tabular}{|c|c|c|c|c|c|c|c|c|c|c|c|c|c|c|}
\hline \multirow[b]{4}{*}{ 竎 } & \multicolumn{12}{|c|}{ مكونات الوحدة التدريبية اليومية } & \multirow{4}{*}{$\begin{array}{l}\text { أسابيع } \\
\text { المرحلة }\end{array}$} & \multirow{4}{*}{ مراحل البرنامـج } \\
\hline & الختامى & الرئيسي & & & & & & & & & & الإحماء & & \\
\hline & \multirow[b]{2}{*}{ 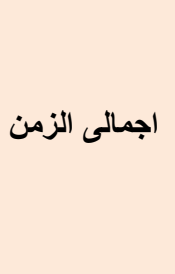 } & \multirow{2}{*}{ 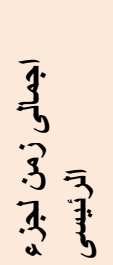 } & \multicolumn{3}{|c|}{ إعداد خططي } & \multicolumn{3}{|c|}{ إعداد مهارى } & \multicolumn{3}{|l|}{ إعداد باني } & \multirow[b]{2}{*}{ 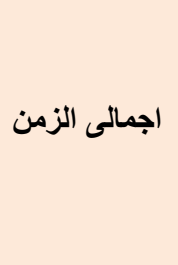 } & & \\
\hline & & & 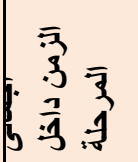 & $\begin{array}{ll}\overline{3} \\
\cdot 3 \\
\overline{1} & \overline{3} \\
\overline{3} & 1\end{array}$ & 雪 & $\begin{array}{l}\overline{3} \\
\overline{3} \\
\overline{3} \\
\overline{3}\end{array}$ & $\begin{array}{ll}\overline{3} \\
\cdot 3 \\
\frac{7}{3} & \overline{1} \\
\frac{1}{3} & 10\end{array}$ & 哥. & 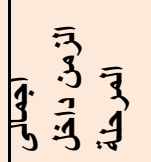 & $\begin{array}{ll}\overline{3} \\
.3 \\
\frac{1}{3} & \overline{1} \\
\frac{3}{3} & : 0\end{array}$ & 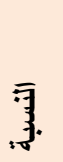 & & & \\
\hline
\end{tabular}


أميرة عبد الحميد شوقى عبد العزيز

\begin{tabular}{|c|c|c|c|c|c|c|c|c|c|c|c|c|c|c|c|}
\hline • ؛ ؛ اق & יד ق & 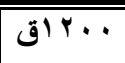 & - & - & - & יצ"ה & • "كق & $\%^{\mu}$. & . ع ^ق . & • V . & $\%$ \%. & .1/اق & $r$ & مرحلة تأسيسية & \multirow{3}{*}{ البرنامج } \\
\hline 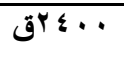 & •" ق & ..... & ل · & r بق & $\%^{r}$. & 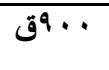 & 0 ؛ق & $\% \leqslant 0$ & ل . . & هبق & $\%^{\text {Yo }}$ & & 0 & مرحلة إعداد خاص & \\
\hline 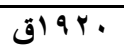 & م. & ل. & . & ידق & $\%^{4}$ & • r rاق & r raق & $\%^{\varphi}$. & 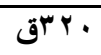 & • بق & $\%^{\varphi}$. & 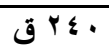 & $\varepsilon$ & مرحلة إعداد للمنافسات & \\
\hline lov4. & 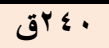 & 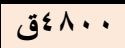 & צrاق & & & ليماق & & & 4هاق & & & lar. & Tr & المجموع & \\
\hline
\end{tabular}

ونظر الطبيعية البحث ومتغير اته واهدافة والتى حددت المهارة الضربة الهجومية كمتغير مستقل و التمرينات النوعية كمتغير تابع ( تجريبى ) الأمر الذى يتطلب تتفيذه خلال زمن كل من الجزء المخصص للإعداد البدنى و المهارى داخل مر احل البرنامج المقترح

سابعاً : المعالجات الأحصائية :

فقامت الباحثه بأستخدام البرنامج الإحصائى

المتوسط الحسابى (س) ، الأنحر اف المعيارى ( 土 ع ) ، معامل الألتواء ، معامل التفلطح ، معامل الاختلاف،اختبار ت للفروق للقياس القبلى والبعدى لمجموعة وحدة، نسبة التحس \% ، معامل إيتا ، معامل التاثير

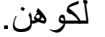


رأفت محمد توفيق حمزة

ثامناُ : عرض ومناقشة النتائج

عرض النتائج :

\section{جدول (v)}

الالالات الإحصائية الخاصة باختبار ات القدرات النفس حركية بدلالة منظومة فيينا

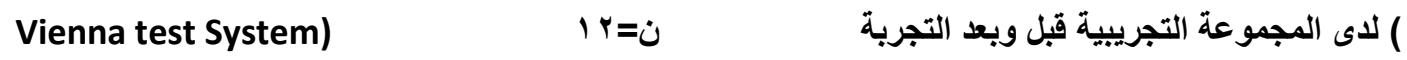

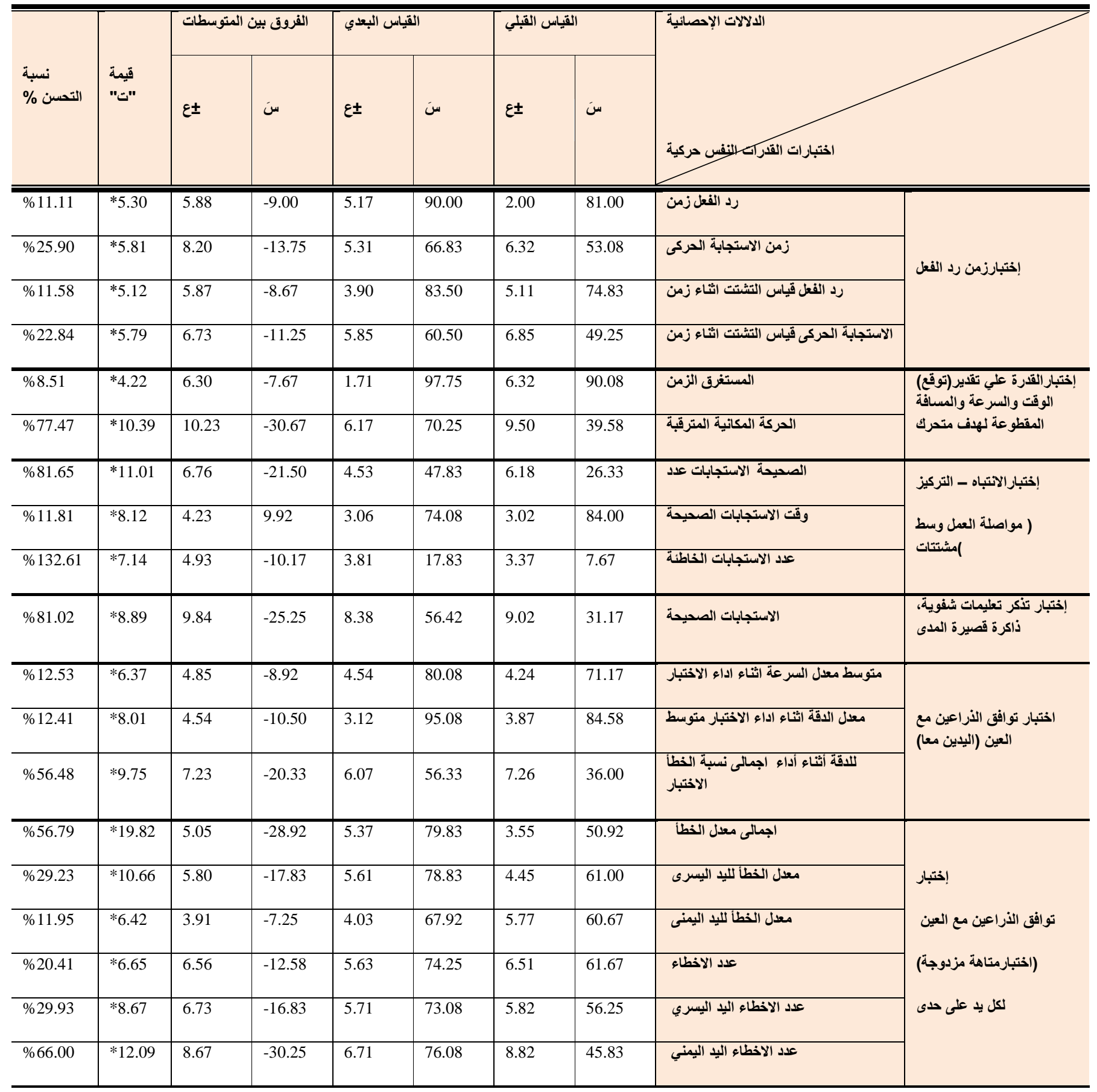




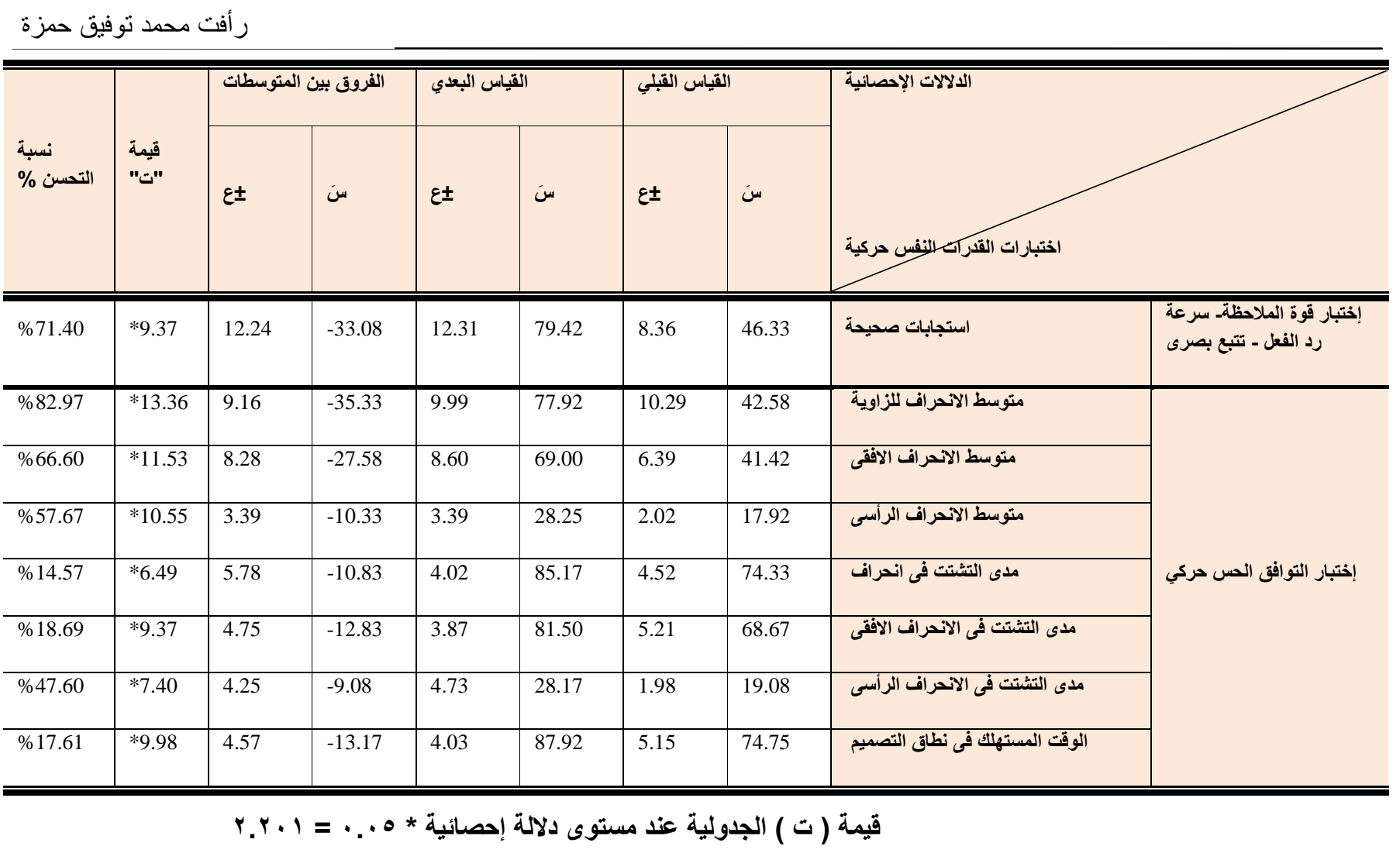

عايتضح من الجدول رقم (Vienna test

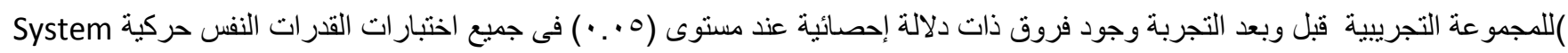

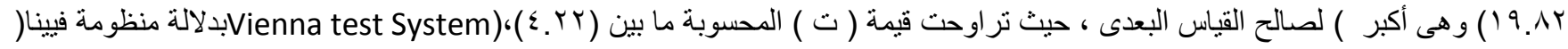

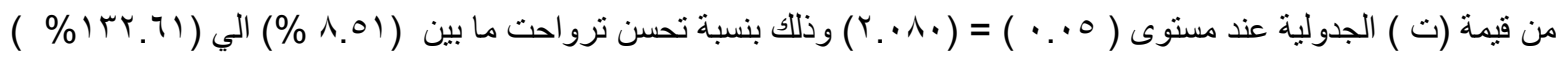




\section{جدول (^)}

معامل أيتام وحجم التأثير لكوهن الخاص باختبارات القدرات النفس حركية بدلالة منظومة فيينا

Vienna test System لاى المجموعة التجريبية قبل وبعد التجربة

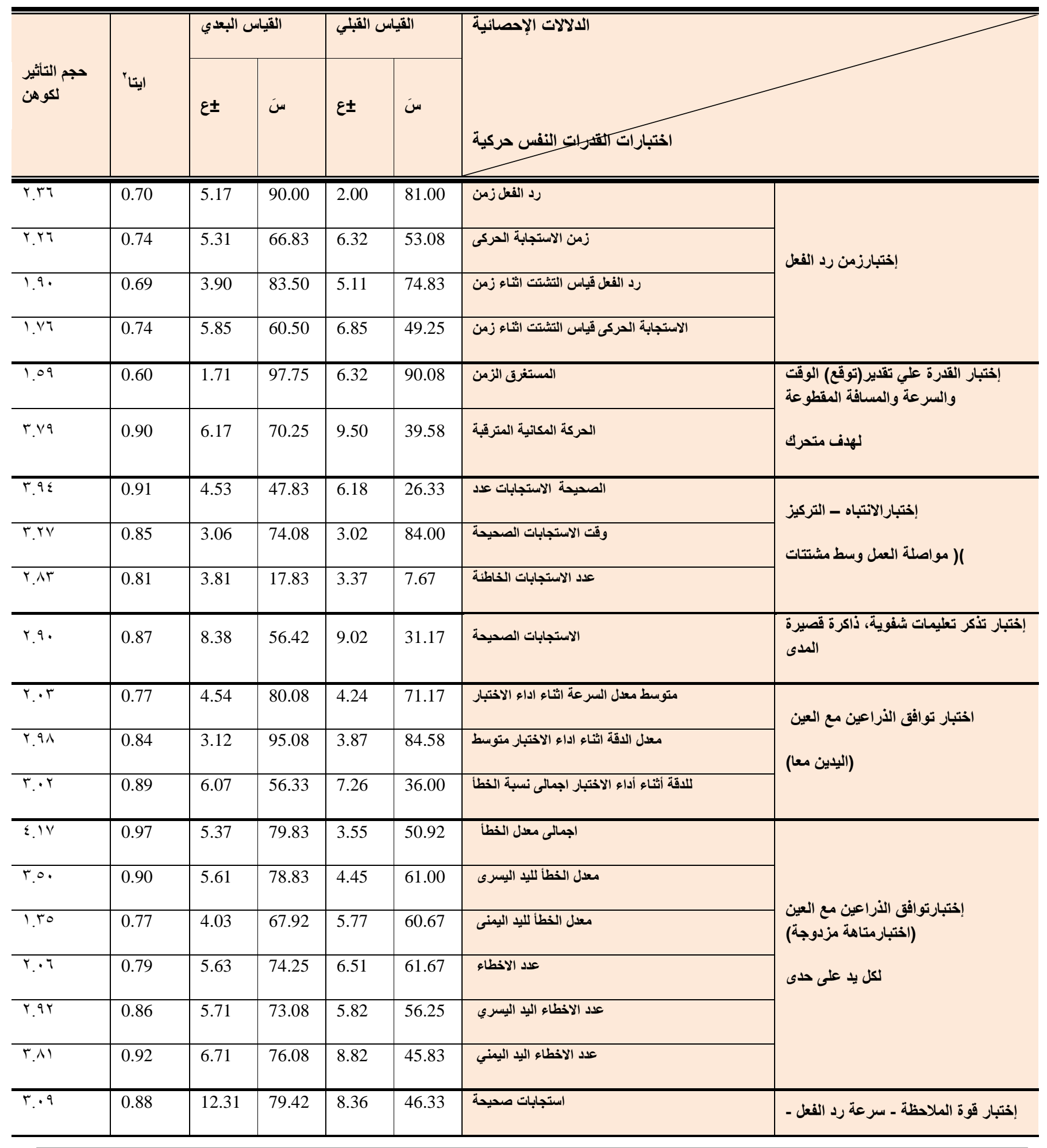




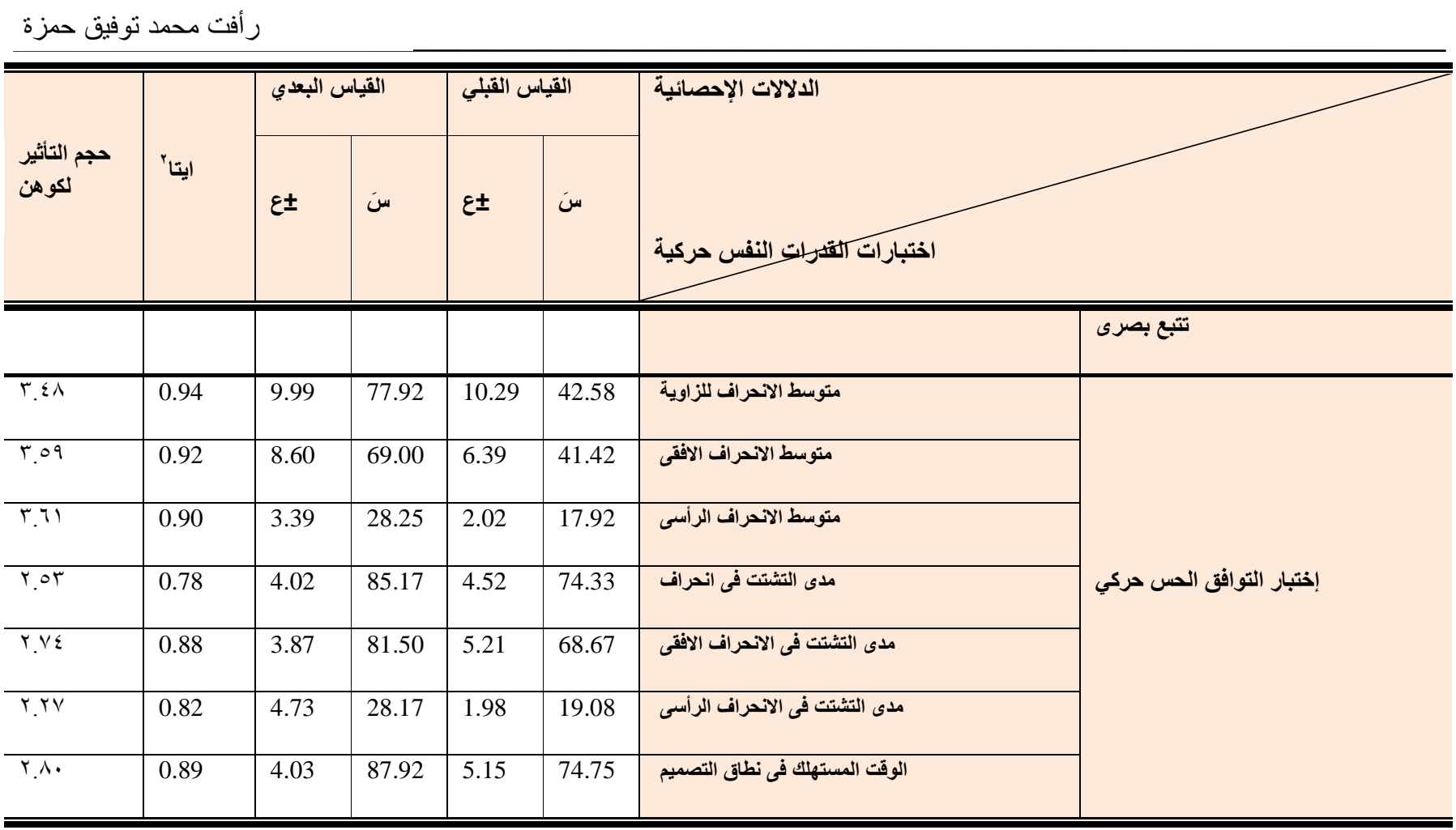

يتضح من الجدول رقم (^) الخاص بمعامل أيتا وحجم النأثير لكوهن الخاص باختبار ات القدرات النفس حركية بدلالة منظومة فيينا(

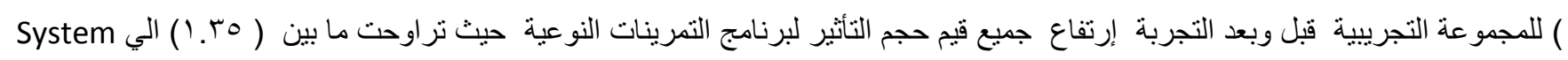

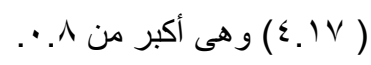




\section{جدول (9)}

الالالات الإحصائية الخاصة بمستوى أداء مهارة الضربة الهجومية لاى عينة الدراسة الأساسية

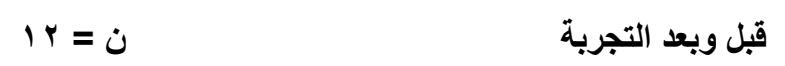

\begin{tabular}{|c|c|c|c|c|c|c|c|c|c|c|c|}
\hline \multirow[b]{2}{*}{ التحسنة نسبة } & \multirow[b]{2}{*}{ قيمة "ت" } & \multirow[b]{2}{*}{ الفروق } & \multirow[b]{2}{*}{ الفروق } & \multicolumn{2}{|c|}{ القياس البعدي } & \multicolumn{2}{|c|}{ القياس القبلي } & \multirow[b]{2}{*}{ القياس } & \multicolumn{3}{|l|}{ الدلالات الإحصائية } \\
\hline & & & & $\varepsilon \pm$ & 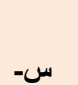 & $\varepsilon \pm$ & س- & & & & \\
\hline$\% 86.77$ & $* 9.53$ & 1.14 & -3.13 & 1.08 & 6.73 & 0.73 & 3.60 & (درجة) & إلى مركز ( 1 ) & \multirow{3}{*}{.3} & \multirow{6}{*}{ 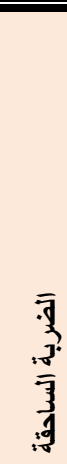 } \\
\hline$\% 42.36$ & $* 10.63$ & 0.89 & -2.74 & 0.79 & 9.22 & 0.83 & 6.48 & (درجة) & إلى مركز (• ) & & \\
\hline$\% 26.44$ & $* 5.83$ & 0.91 & -1.53 & 0.95 & 7.33 & 1.16 & 5.80 & (درجة) & إلى مركز ( " ) & & \\
\hline$\% 69.21$ & $* 10.55$ & 0.97 & -2.95 & 0.71 & 7.21 & 1.19 & 4.26 & (درجة) & إلى مركز ( 1 ) & \multirow{3}{*}{$\begin{array}{l}3 \\
3 \\
3 \\
3 \\
0\end{array}$} & \\
\hline$\% 33.65$ & $* 13.00$ & 0.59 & -2.21 & 0.26 & 8.78 & 0.72 & 6.57 & (درجة) & إلى مركز (• ) & & \\
\hline$\% 56.82$ & $* 13.76$ & 0.81 & -3.22 & 0.51 & 8.88 & 0.74 & 5.66 & (درجة) & إلى مركز ( " ) & & \\
\hline$\% 47.66$ & $* 11.54$ & 0.78 & -2.61 & 0.65 & 8.10 & 0.74 & 5.48 & (درجة) & إلى مركز ( 1 ) & \multirow{3}{*}{$\begin{array}{l}3 \\
3 \\
3 \\
3 \\
=\end{array}$} & \multirow{6}{*}{$\begin{array}{l}\overline{7} \\
\bar{\gamma} \\
\overline{7} \\
\overline{7}\end{array}$} \\
\hline$\% 55.30$ & $* 8.67$ & 1.01 & -2.54 & 0.66 & 7.13 & 0.85 & 4.59 & (درجة) & إلى مركز (• ) & & \\
\hline$\% 46.63$ & $* 8.87$ & 1.11 & -2.85 & 0.47 & 8.97 & 0.90 & 6.12 & (درجة) & إلى مركز ( " ) & & \\
\hline$\% 72.87$ & $* 8.45$ & 1.30 & -3.17 & 1.03 & 7.51 & 0.95 & 4.35 & (درجة) & إلى مركز ( 1 ) & \multirow{3}{*}{ 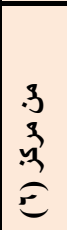 } & \\
\hline$\% 52.29$ & $* 6.13$ & 1.58 & -2.79 & 0.79 & 8.13 & 1.15 & 5.34 & (درجة) & إلى مركز (• ) & & \\
\hline$\% 40.92$ & $* 13.18$ & 0.71 & -2.68 & 0.50 & 9.24 & 0.54 & 6.56 & (درجة) & إلى مركز ( " ) & & \\
\hline
\end{tabular}

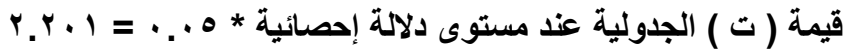

يتضح من الجدول رقم (9) وجود فروق دالة إحصائيا عند مستوي ه . . بين القياسين القبلي و البعدي لصالح القياس البعدي في مستوى الأداء

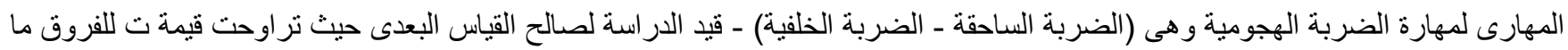

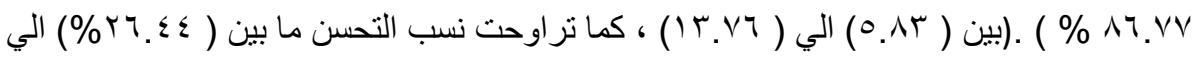




\section{جدول (· (1)}

معامل أيتاب وحجم التأثير لكوهن الخاص بمستوى أداء مهارة الضربة الهجومية لاى عينة الار اسة الأساسية قبل وبعد التجربة

\begin{tabular}{|c|c|c|c|c|c|c|c|c|c|}
\hline \multirow{2}{*}{ حجم التأثير } & \multirow[b]{2}{*}{ معامل ايتا' } & \multicolumn{2}{|c|}{ القياس البعدي } & \multicolumn{2}{|c|}{ القياس القبلي } & \multirow{2}{*}{ القياس } & \multicolumn{3}{|l|}{ الالالات الإحصائية } \\
\hline & & $\varepsilon \pm$ & س- ا س & $\varepsilon \pm$ & س- ا س & & & & \\
\hline r.ro & 0.88 & 1.08 & 6.73 & 0.73 & 3.60 & (درجة) & إلى مركز ( 1 ) & \multirow{3}{*}{$\begin{array}{l}3 \\
3 \\
3 \\
3 \\
2 \\
2\end{array}$} & \multirow{6}{*}{ 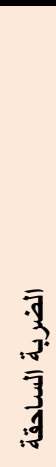 } \\
\hline r. $\varepsilon$. & 0.90 & 0.79 & 9.22 & 0.83 & 6.48 & (درجة) & إلى مركز (• ) & & \\
\hline $1 . \varepsilon r$ & 0.74 & 0.95 & 7.33 & 1.16 & 5.80 & (درجة) & إلى مركز ( " ) & & \\
\hline Y.V9 & 0.90 & 0.71 & 7.21 & 1.19 & 4.26 & (درجة) & إلى مركز ( 1 ) & \multirow{3}{*}{$\begin{array}{l}3 \\
3 \\
3 \\
3 \\
0\end{array}$} & \\
\hline$r .19$ & 0.93 & 0.26 & 8.78 & 0.72 & 6.57 & (درجة) & إلى مركز (• ) & & \\
\hline 0.4 & 0.94 & 0.51 & 8.88 & 0.74 & 5.66 & (لدرجة) & إلى مركز ( " ) & & \\
\hline r.Vo & 0.92 & 0.65 & 8.10 & 0.74 & 5.48 & (درجة) & إلى مركز ( 1 ) & \multirow{6}{*}{ 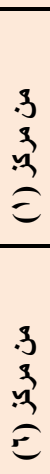 } & \multirow{6}{*}{ 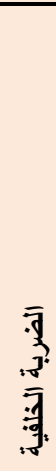 } \\
\hline$r . r \mu$ & 0.86 & 0.66 & 7.13 & 0.85 & 4.59 & (درجة) & إلى مركز (• ) & & \\
\hline$\varepsilon . \varepsilon$ & 0.87 & 0.47 & 8.97 & 0.90 & 6.12 & (درجة) & إلى مركز ( " ) & & \\
\hline 5.19 & 0.86 & 1.03 & 7.51 & 0.95 & 4.35 & (درجة) & إلى مركز ( 1 ) & & \\
\hline r.AT & 0.76 & 0.79 & 8.13 & 1.15 & 5.34 & (درجة) & إلى مركز (• ) & & \\
\hline 0.10 & 0.94 & 0.50 & 9.24 & 0.54 & 6.56 & (درجة) & إلى مركز ( " ) & & \\
\hline
\end{tabular}

يتضح من الجدول رقم (• () الخاص بمعامل أيناب وحجم التأثير لكو هن الخاص بمستوى أداء مهارة الضربة الهجومية للمجموعة التجريبية قبل

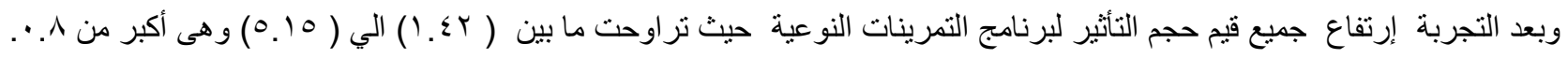


فى ضوء العرض السابق لمجموع النتائج التى توصلت إليها الباحثه فى إطار أهداف البحث وفروض ومنهجه و أسترشادا بنتائج الدراسات السابقة

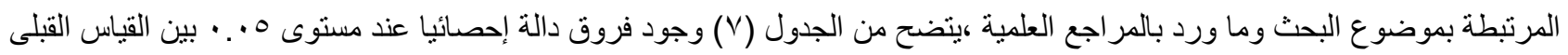
) لمجموعة البحث التجريبية لصالح القياس Vienna test System القياس البعدى فى اختبار ات القدرات النفس حركية بدلالة منظومة فيينا(

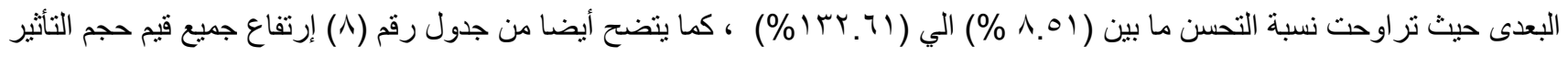

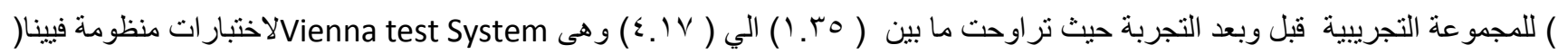
أكبر من ^

وترجع الباحثه التحسن في القدرات النفس حركية لاى أفراد عينة البحث إلى التأثير الفعال للبرنامج التمرينات النوعية وما يتطلبه من قدرات

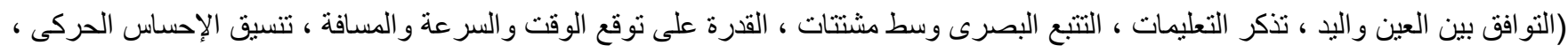

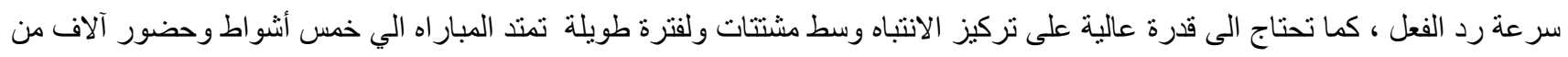
المشاهدين ، كما تم التدريب علي البرنامج التدريبي لمدة إثني عشر اسبوع بصورة منظمة ومجمعه بحيث تم ، كل ذللك أسهم في تحسن القدرات

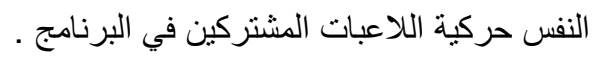

حيث أن التدريب علي التمرينات والمهار ات الحركية بشكل منتظم ومستمر له دورا هاما في تحسين القدرات النفس حركية و الإرتقاء بالأداء

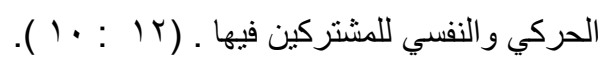

كما ان للتمرينات البدنية دور كبير فى تطوير المتغيرات الحس حركية بما تحتوية من تشكيلات وتكوينات متداخلة ومتنوعة واستخدام مثيرات

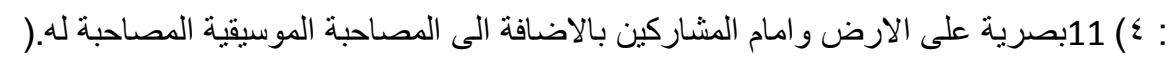

كما ان للتمرينات النوعية بأنو اعها المختلفة لها أثر كبير في تتمية الانتباه وتحكم التصور البصري لاى المشاركين وذلك من خلال التدريب الموجه،

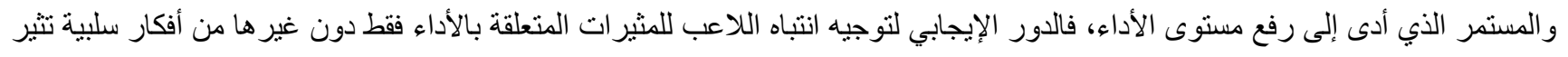

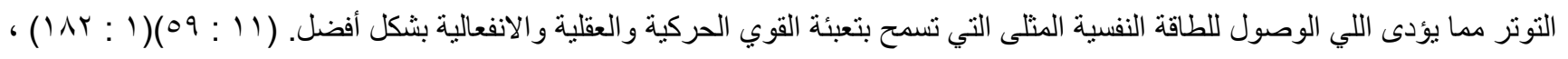
$($ (rฯ : r)

) ولوا ما تؤكده العديد من الدر اسات لوجود ارتباطات مختلفة في القدرات النفس حركية للرياضين في الاستجابة على اختبار ات منظومة فيينا (

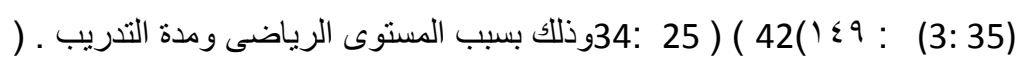

ويؤكد بعض الباحثين أن بر امج التدريب البصرية والتي تهذف الي التدريب على المشتتات البصرية تؤدي الي تحسين الادر الك البصرى وسرعة

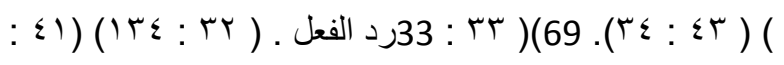

توجد فروق دالة إحصائياً بين القياسين القبلى والبعدى لمجموعة البحث لصالح وبالتالي تكون قد تحققت نتائج الفرض الأول و الذى ينص على أنه القياس البعدى فى بعض القدرات النفس حركية بلالاية منظومة فيينا للاعبات الكرة الطائرة.

كما يتضح من الجدول (9) وجود فروق دالة إحصائيا عند مستوى ه . • بين القياس القبلى والقياس البعدى فى مستوى أداء مهارة الضربة

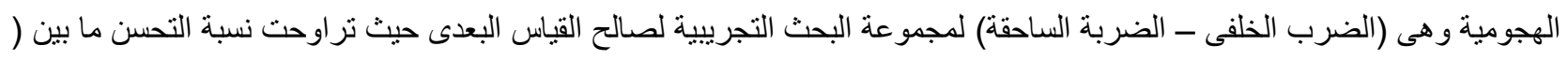

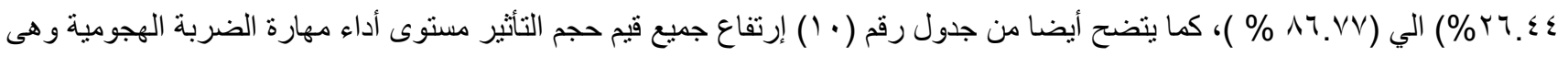

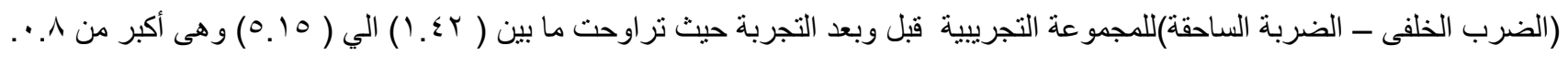


رأفت محمد نوفيق حمزة

وتعزو الباحثه هذة الفروق بين القياس القبلى والقياس البعدى في مستوى أداء مهارة الضربة الهجومية وهى (الضرب الخلفى ـ الضربة الساحقة)

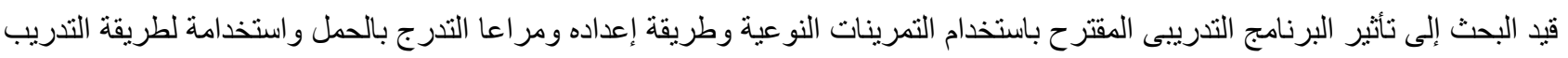
الفترى مرتفع الثندة ، وتتكيل الراحات البينية بين التمرينات و المجموعات و التى إحتوت على تمرينات المرونة والاطالة ،و استخدامة لادو ات

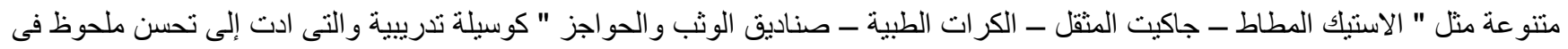

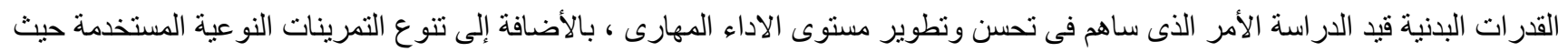
إثتملت على ( تمرينات حرة و بالأدو ات ـ تمرينات فردية وزوجية ) وذللك من خلال نوظيفها كتمرينات مشابهة لطبيعة الأداء المهارى وفى إتجاه

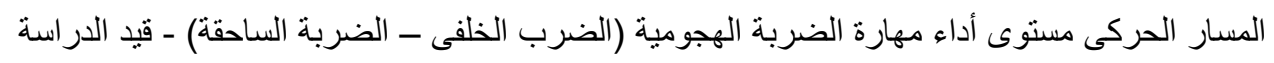

وتنفق نتائج هذا البحث مع ما ذكره كل من زكى محمد محمد حسن (1991) ، عبد العزيز النمر ناريمان الخطيب (1997 () ، عصام الدين عبد

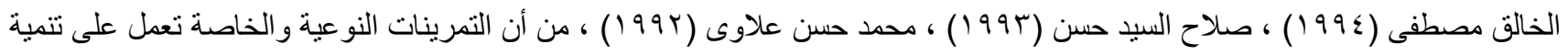

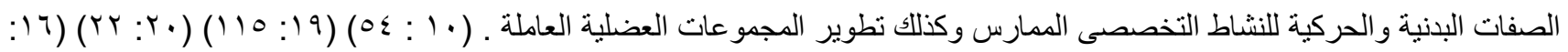
$(1 \cdot r: r \varepsilon)(r)$

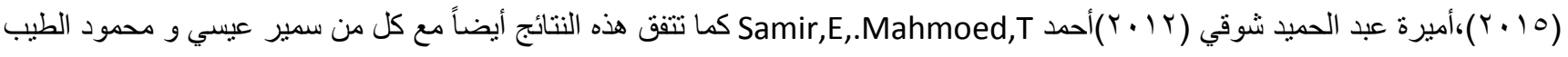
إبر اهيم وامر الله البساطى (990 (1))، على أن استخدام التمرينات المشابة للأداء ولنوعية النشاط المختار هو الأسلوب الأمثل للتقام بالأداء مع مر اعاة

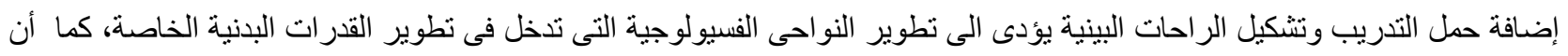

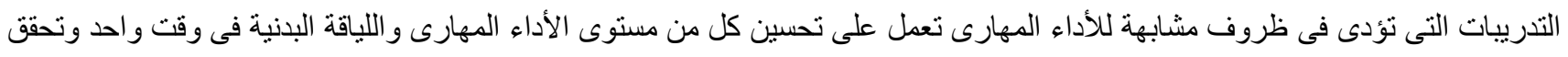
التزامن بين الخصائص البدنية وترقية مستوى الأداء المهارى.

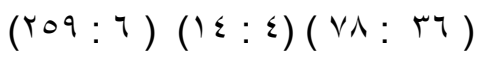

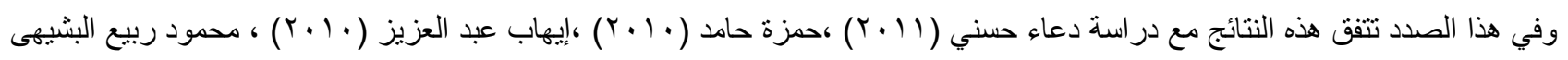

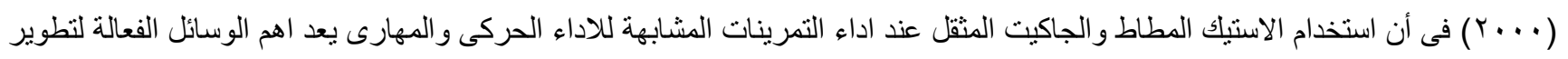
القدرات الحركية وتحسن مستوى وفاعلية الاداء المهارى.( :

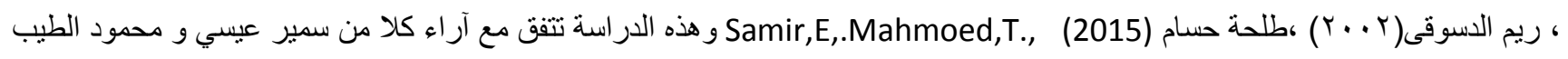
الدين ( ب99 (1) بأن التمرينات النوعية المشابهة للأداء المهارى فى التدريب نؤدى إلى تحسن مستوى الأداء المهارى ويؤثر تأثير ا إيجابيا فى رفع

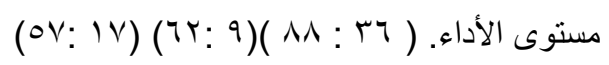

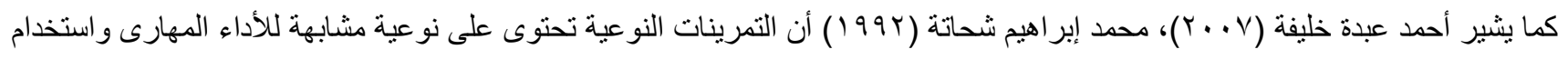

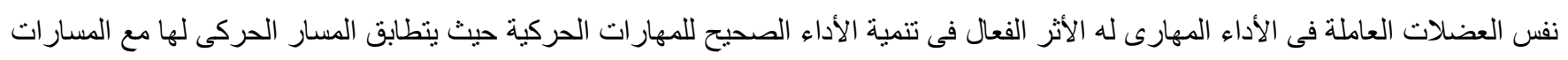

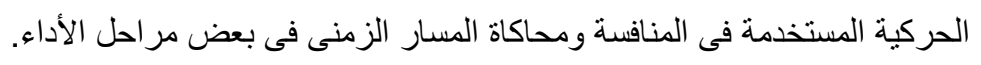

$(\varepsilon r r: r r)(r r: r)$

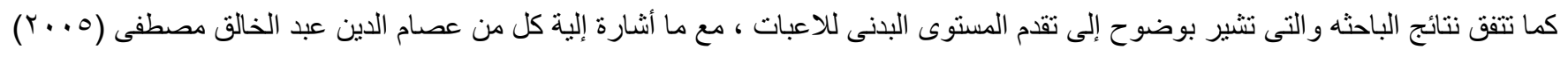

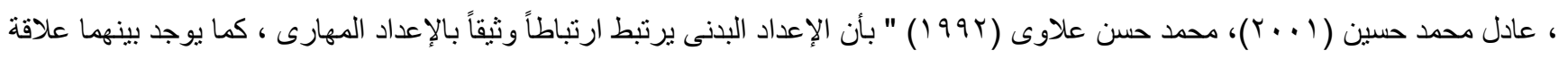
طردية موجبة فكلما ارتفع المسنوى البدنى للاعبين وتحسنت لديهم اللياقة البدنية كلما زادت قدرتهم على تعلم و إتقان الأداء الفنى للمهار ات الحئ الحركية $(Y \circ V: Y \varepsilon)(Y V: 1 \Lambda)(I V T: Y \cdot)$." 
رأفت محمد نوفيق حمزة

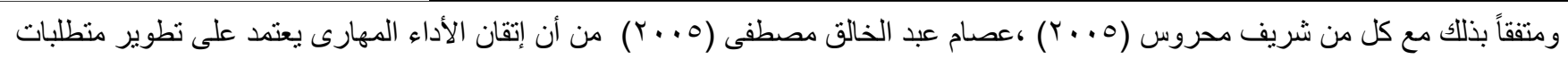

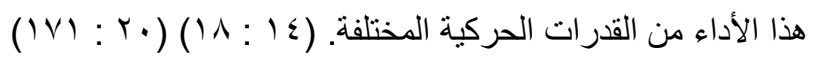

وبالتالي تكون قد تحققت نتائج الفرض الثاني و الذى ينص على أنه توجد فروق دالة إحصائياً بين القياسين القبلى والبعدى لمجموعة البحث لصالح القياس البعدى فى مستوى أداء مستوى أداء مهارة الضربة الهجومية للاعبات الكرة الطائرة. تاسعاً :الإستنتاجات

ا- البرنامج التدريبى المقترح بإستخدام التمرينات النو عية أثر على تحسين القدرات النفس حركية بدلالة اختبار ات منظومه فيينا Vienna test system r- البرنامج التذريبى المقترح بإستخدام التمرينات النوعية أدى لتحسين وتطوير مستوى الأداء مهارة الضربة الهجومية (الضربة الساحقة ـ

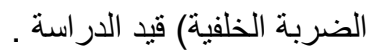

ك-ـ ان استخدام التقنيات الحديثة كمنظومة فيينا ( Vienna test system ) ، ساعدت في الحصول على النتائج الاقيقة و الحقيقية لمتغير ات الدارسة التي كان من الصعب قياسها بنفس الدقة و المصداقية باستخدام الوسائل التقليدية .

عاشراً : التوصيات

ا - إستخدام البرنامج التدريبى المقترح " التمرينات النوعية" و التي تسهم في تحسين القدرات النفس حركية بدلالة اختبار ات منظومه فيينا

Vienna test system ) الخاصة بمهارة الضربة الهجومية (الضربة الساحقة - الضربة الخلفية) قيد الدراسة. ك- أستخدام البرنامج التدريبى المقترح " التمرينات النوعية" لتحسين مهارة الضربة الهجومية (الضربة الساحقة ـ الضربة الخلفية ) قيد الدر اسة.

r- استخدام منظومة فيينا ( Vienna test System ) و المعنية بالفحص و القياس و التشخيص عند إجر اء أب قياس نفسي او معرفي، وذلك

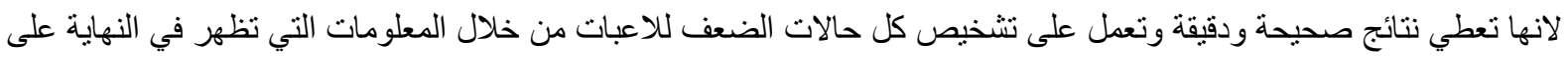

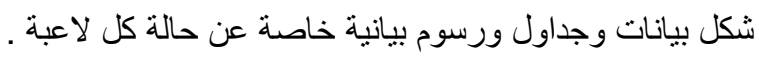
عـ - ضرورة استخدام التقنيات الحديثة عند القيام بإجر اء أب إختبار ات نفسية وذللك لأنها تتسم بالدقة و المصداقية وتعطي نتائج حقيقية ودقيقة وملموسة، بدلا من استخدام الوسائل التقليدية المعروفة و المتبعة في السابق ، و التي لا تعطي نفس الدقة و المصداقية التي تعطيها التقنيات الحديثة. 0ـ إجر اء إختبار ات دورية على اللاعبات و على فترات منتظمة وفق منظومة فيينا(Vienna test System) للقياس و الفحص و التنتخيص، لمعرفة مستوى أداء اللاعبات في القدرات النفس حركية من اجل تطوير البرامج التدريية لديهم. 7- أجر اء در اسات مماتلة على مهار ات أخرى ومر احل عمرية مختلفة لناشئى الكرة الطائرة بإستخدام أشكال مختلفة من التمرينات البدنية . 


\section{أو لا:المر اجع العربية:}

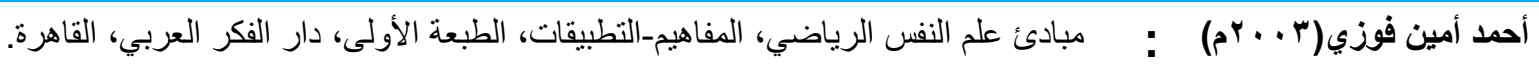

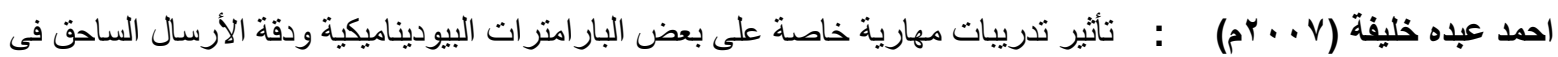

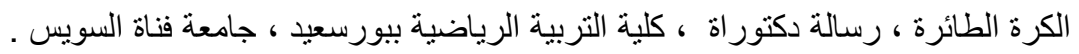

تدريب المهارات النفسية، نطبيقات في المجال الرياضي، الطبعة الأولى، دار الفكر العربي،

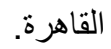

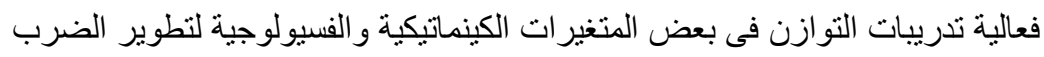

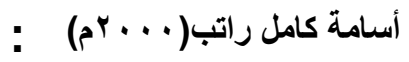

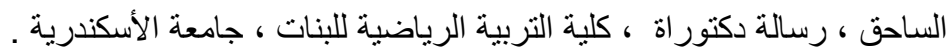

تأثير برنامج تدريبى باستخدام أسلوبى المقاومات الباليستية والبليومترية فى تتمية القدرة

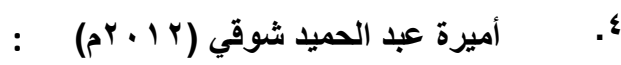

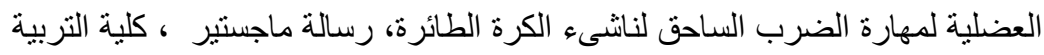

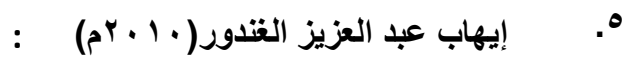

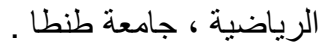

تاثثير توجية احمال تدريبية وفقا لنمط الايقاع الحيوى على قيم بعض الدلالات الوظيفية

: أمرالله أحمد أحمد محمود ابراهيم

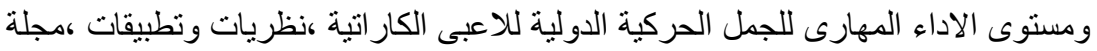

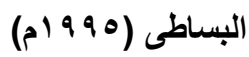

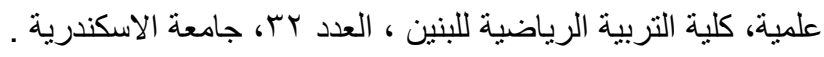

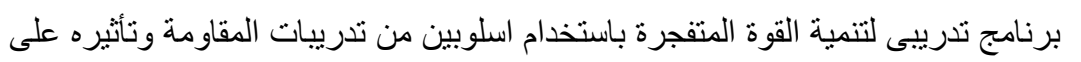

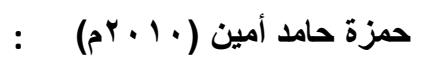

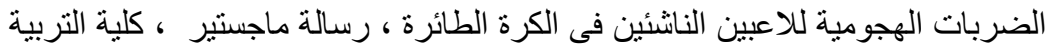

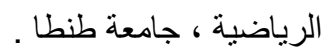

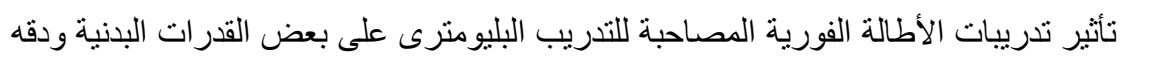

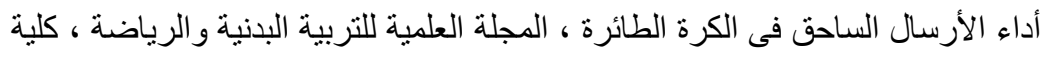

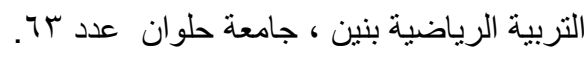

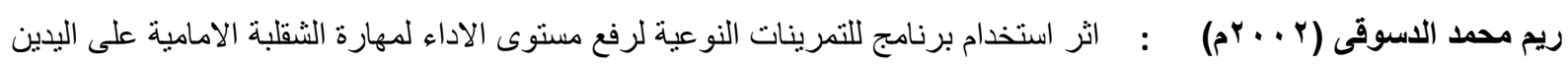

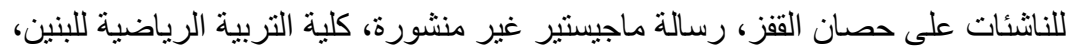

جامعة الإسكندرية.

الكرة الطائرة بناء المهارات الفنية والخططية منشأة المعارف ، الأسكندرية .

: عى محمد حسن (991)

$.1 \cdot$

تأثثر العروض الرياضية على ديناميكية تطوير بعض متغير ات الإدرات (الحس - حركي)

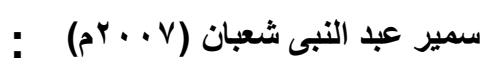

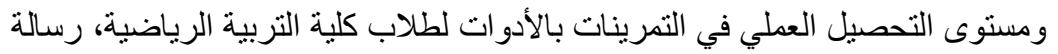

دكتور اه، كلية التربية الرياضية، جامعة الإسكندرية.

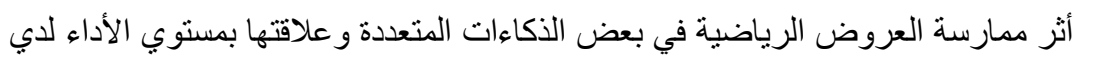

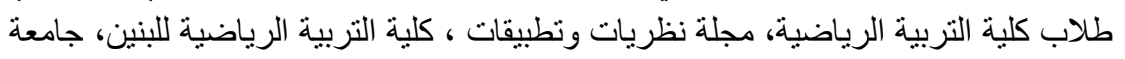

سمير عبد النبى شعبان (10 + م م) ) الإسكندرية .

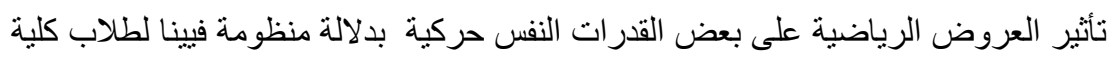

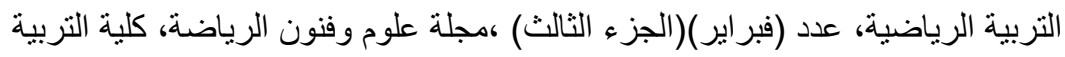

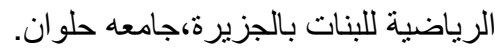

: دراسة مقارنة لتأثير التدريب بالأثقال و البليوفري علي تتمية القدرة العضلية ومستوي آداء

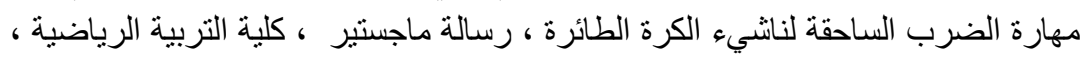


رأفت محمد نوفيق حمزة

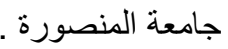

المبادئ و الأسس العلمية للتمرينات البدنية و العروض الرياضية ،دار الوفاء لانبا الطباعة

:

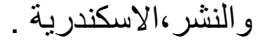

الأسس العلمية الحديثة للتقويم فى الأداء الحركى ، مكتبة النهضة المصرية ، القاهرة .

: : صلاح السيد حسن (ب (99 (م)

.17

التمرينات النوعية وعلاقتها بمستوى التحصيل الحركى للجمباز ، المجلة العلمية للتربية

IV

و الرياضية، بحوث مؤتمر رؤية مستقبلية للتربية البدنية والرياضة في الوطن العربى، المبلى المجلد

الثانى الثى

عادل محمد حسين (1 + . rم) تأثير برنامج مقترح للقدرة العضلية على تحقيق المستهدف من الضرب الساحق للاعبى الكرة

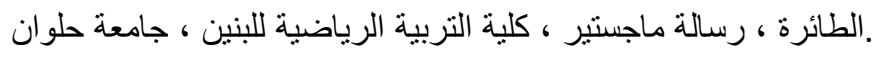

: التدريب الرياضى ، تدريب الأثقال (تصميم بر امج القوة وتخطيط الموسم الرياضى) ، مركز

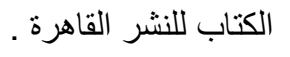

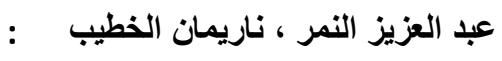

: التدريب الرياضى (نظريات وتطبيقات) الطبعة الثامنة ، دار المعارف ، الإسكندرية .

(م) (997)
القاهرة G.M.S التدريب الرياضى (النظرية و التطبيق) ، دار.
التحليل المهارى للجمباز، دار المعارف، الاسكندرية.
التدفق النفسي في المجال الرياضي (التجربة الفينومينولوجية) دار الوفاء لانيا الطباعة و
النشر، الإسكندرية، مصر.

: : عصام الدين عبد الخالق مصطقى

.$r \cdot$

$$
\text { (P. P.) }
$$

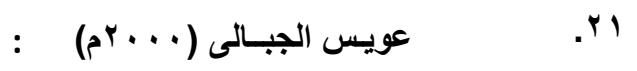

علم التدريب الرياضى ، الطبعة الثانية عشرة ، دار المعارف ، القاهرة .

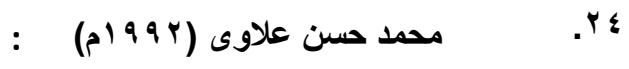

تأثثر التمرينات التخصصية على الضرب الساحق من المنطقة الخلفية فى الكرة الطائرة ،

: محمد عبد المحسن عبد الرحمن

رسالة ماجستير غير منشورة ، كلية التربية الرياضية ، جامعة المنيا. (Pr. (1)

تأثير الأحبال المطاطة على القدرة العضلية ومستوى الأداء فى رياضة الكار اتيه، رسالة

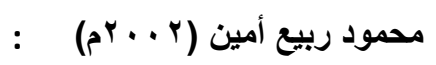

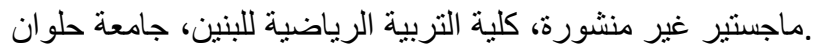

بناء نماذج حركية بيوميكانيكية لتقييم مستوي بعض الأداءات المهارية لدي لاعبي الكرة

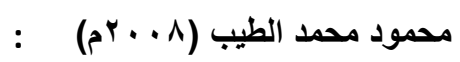

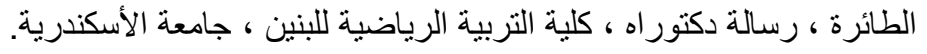

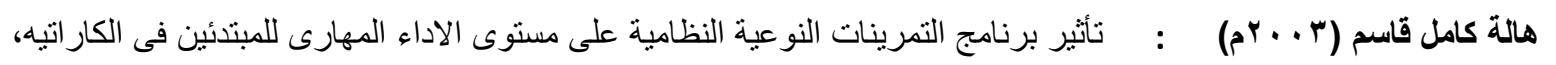

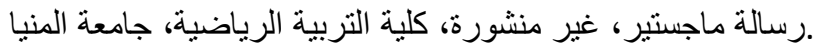

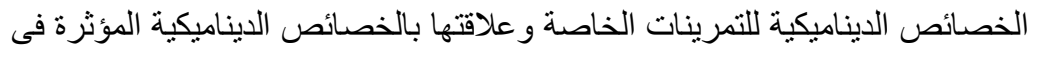

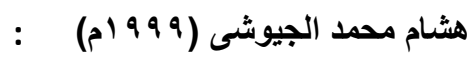

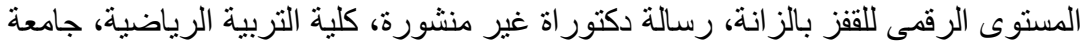

حلو ان.

تأثير برنامج للتدريبات النوعية باستخدام جهاز بديل على مستوى أداء مهارة الثقلبة

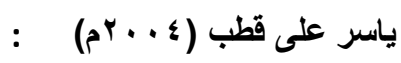

$r$

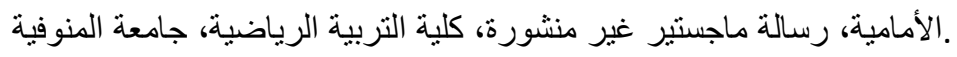


رأفت محمد توفيق حمزة

ثانياً :المر اجع باللغة الاجنية

31. Biddle, Start (1996)

32. Blundell N.L., (2012)

: Psychology of physical Education and Sports: A Practical Guide for Teachers", 3rd ed, F.I.T. Systems Ltd, U.K.

: A multivariate analysis of the visual perceptual attributes of male and female tennis players of varying ability levels. Psychology of Motor Behaviour and Sport: North American Society for the Psychology of Sport and Physical Activity. University of Maryland, $.134-142$

33. Hitzeman S.A., Beckerman S.A., (2003)

: What the literature says about sports vision. Optom Clin. 3(1): 69.

34. Johne M, Poliszczyk T, Poliszczuk D, DąbrowskaPerzyna A.,( 2013)

: Asymmetry of complex reaction time in female epee fencers of different sport classes. movement anticipation in elite female basketball players. Pol J Sport Tourism;20:25-34.

35. Mańkowska M, Poliszczuk T, : Visual perception and its effect on re action time and time Poliszczuk D, Johne M.,(2015) movement anticipation in elite female basketball players. Pol J Sport Tourism;22:3-14

36. Samir,E,.Mahmoed,T., (2015)

: Effectiveness of specific exercises on improving performance level of some Volleyball similar performance attack skills, International Journal of Sports science and Arts, Faculty of Physical Education for Girls in Gezira, Helwan University, Egypt.

37. Sanjiv Dutta, Dr.Agyajit Singh(2013)

: A Comparative Study Of Psychomotor Abilities Of School And University Level Athletes, International Journal Of Behavioral Social And Movement Sciences, Vol.02,Nov.

38. Schuhfried, G. (2013)

: Vienna Test System: Psychological assessment. Moedling, Austria: Schuhfried. www.schuhfried.com

39. Schuhfried G. Vienna Test : Paul Gerin Druckerei, Wolkersdorf;. System Sport. Moedling (2013)

40. Sport psychological ability and personality assessment with the Vienna Test System SPORT. (2014)

: Retrieved October 21, 2014, from http://www.schuhfried.com/viennatestsystem10/vienna-testsystem-vts/vienna-test-system-sport/ 
رأفت محمد توفيق حمزة

41. Stine C.D., Arterburn M.R., $\quad$ : Vision and sports: a review of the literature. J Am Optom Assoc. Stern N.S. (2002) 53(8):627-33.

42. Turosz MA, Sadowski J, Graczyk M.,(2007)

43. Williams A.M., (2003)

44. Zatsiordky, V,. (2002)
: Zróżnicowanie i interkorelacje zdolności koordynacyjnych ze zmiennymi psychicznymi w okresie przygotowawczym i startowym Kadry Polski wioślarzy [Individual differences and interactions of coordination abilities and mental variables in preparatory and starting periods of Polish national team rowers]. Medycyna Sportowa.;3(6):149-154

: Perceptual expertise. In: Expert performance in sports.(ed Starkes, J.L. and Ercisson, K.A.). Human Kinetics: Champaign, Illinois, 34.

: Kinetics of human motion, human kinetics, USA.

\section{ثالثاً :مر اجع شبكة المعلومات الدولية}

45. http://www.fivb.org/en/volleyball/VB_Ranking_M_2011-12.asp

46. http://www.iraqacad.org/Journal/babil/babi105/2005406. pdf 


\section{ملخص البحث باللغة العربية}

يهدف البحث إلي التعرف على تأثير التمرينات النوعية علي بعض القدرات النفس حركية بدلالة منظومة فيينا ومستوى أداء مهارة الضربة الهجومية للاعبات الكرة الطائرة ، تم اختيار عينة البحث بالطريقة العدية لفريق كلية التربية الرياضية للبنات للكرة الطائرة والمشارك في بطولتي الكليات المتخصصة والجامعات ، حيث بلغ أجمالى عدد العينة ( با لاعبه ) مسجلين ضمن فرق نادي سموحة الرياضي ونادي الجياد ،إستخدت الباحثة المنهج التجريبى ذو التصميم التجريبى للمجموعة الو احدة بالقياسات القبليه البعدية وذلك لملائيته لطبيعة ، وقامت الباحثة بتصميم برنامج

تمرينات نوعية وتم التدريب عليه لمدة ( r ا) أسبو ع، بو اقع ( ) ) وحدات تدريبية أسبو عية ،وكانت أهم النتائج حققت مجموعة البحث تفوقا في القياسات البعدية على القياسات القبلية في القدرات النفس حركية بدلالة اختبار ات منظومه فيينا Vienna test system )وتطويرمستوى أداء مهارة الضربة الهجومية للاعبات الكرة الطائرة قيد الدراسة (الضربة الساحقة ـ الضربة الخلفية)، ان استخدام التقنيات الحديثة كمنظومة فيينا ( ( Vienna test system ، ساعدت في الحصول على النتائج الدقيقة والحقيقية لمتغير ات الدارسة التي كان من الصعب قباسها بنفس الدقة و المصداقية باستخدام الوسائل التقليدية وكانت أهم التوصيات إستخدام البرنامج التدريبى المقترح " التمرينات النوعية" و التي تسهم في تحسين القدر ات النفس حركية بدلالة اختبار ات منظومه فيينا Vienna test system ) الخاصة بمهارة الضربة الهجومية (الضربة الساحقة ـ الضربة الخلفية) قيد الدر اسة ، أستخدام البرنامج التدريبى المقترح " التمرينات النوعية" لتحسين مهارة الضربة الهجومية (الضربة الساحقة ـ الضربة الخلفية ) قيد الدر اسة،استخدام منظومة فيينا ( Vienna test System ) و المعنية بالفحص و القياس و التشخيص عند إجر اء أب قياس للقدر ات النفس حركية ، وذللك لانها تعطي نتائج صحيحة ودقيقة وتعمل على تشخيص كل حالات الضعف للاعبات من خلال المعلومات التي تظهر في النهاية على شكل بيانات وجداول ورسوم بيانية خاصة عن حالة كل لاعبة ، إجر اء إختبار ات دورية على اللاعبات و على فتر ات منتظمة وفق منظومة فيينا (Vienna test System) للقياس و الفحص و التشخيص، لمعرفة مستوى أداء اللاعبات في القدرات النفس حركية من اجل تطوير البر امج التدريية لديهم ،ضرورة استخدام التقنيات الحديثة عند القيام بإجر اء أي إختبار ات نفسية وذلك لأنها تتسم بالدقة و المصداقية ونعطي نتائج حقيقية ودقيقة وملموسة، بدلا من استخدام الوسائل التقليدية المعروفة و المتبعة في السابق ، و التي لا تعطي نفس الدقة والمصداقية التي تعطيها التقنيات الحديثة، إجر اء دراسات أخرى لمعرفة تأثير أثكال مختلفة من التمرينات البدنية على القدرات النفس حركية الأخرى ومهار ات أخرى ومر احل عمرية مختلفة للاعبات الكرة الطائرة 
رأفت محمد نوفيق حمزة

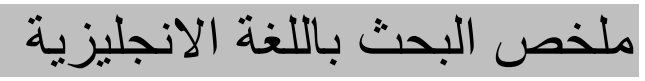

The research aims to identify the impact of qualitative exercises on some psychomotor abilities as a function of the Vienna system and the level of performance of the attack skill of the volleyball players, the research sample was chosen intentionally by the team of the Faculty of Physical Education for Girls Volleyball and participating in the championships of specialized colleges and universities, where the total number of the sample 12 players) registered within the teams of Smouha Sports Club and Aljyad Club, the researcher used the experimental method of experimental design of one group with tribal measurements to fit the nature of the nature, and the researcher designed a qualitative exercise program Training for (12) weeks, by (4) training units per week, the most important results of the research group achieved a superiority in the telemetry measurements of the tribal measurements in the psychomotor abilities in terms of tests Vienna system (Vienna test system) and the development of the performance level of attack skill of the volleyball players Under the study (overwhelming blow - backhand), the use of modern techniques such as the Vienna test system, helped to obtain accurate and real results of the study variables that were difficult to measure with the same accuracy and credibility using traditional means and the most important recommendations using the program The proposed training "qualitative exercises", which contribute to the improvement of psychomotor abilities as a function of the Vienna system tests (Vienna test system) for the skill of the attack strike (overwhelming - back strike) under study, the use of the proposed training program "qualitative exercises" to improve the skill of the attack strike (strike Overwhelming - backhand (under study, the use of the Vienna test system) for testing, measurement and diagnosis when conducting any measurement of psychomotor capabilities, because it gives accurate and accurate results and works to diagnose all weaknesses of the players through the information shown in the In the form of data, tables and special graphs on the status of each player, conduct periodic tests on the players and at regular intervals according to the Vienna test system for measurement, examination and diagnosis, to know the level of performance of players in the psychomotor abilities in order to develop their training programs, the need to use Modern techniques when conducting any psychological tests because they are accurate and credible and give real, accurate and tangible results, instead of using traditional methods known and followed in the past, which do not give the same accuracy and credibility as given by modern techniques, conduct other studies The effect of different forms of physical exercise on the capacity of self-mobility and other skills and other stages of different age players for volleyball. 